\title{
Strength of jointed rock masses
}

\author{
E. HOEK*
}

Jointed rock masses comprise interlocking angular particles or blocks of hard brittle material separated by discontinuity surfaces which may or may not be coatcd with weaker materials. The strength of such rock masses depends on the strength of the intact pieces and on their freedom of movement which, in turn, depends on the number, orientation, spacing and shear strength of the discontinuities. A complete understanding of this problem presents formidable theoretical and experimental problems and, hence, simplifying assumptions arc required in order to provide a reasonable basis for estimating the strength of jointed rock masses for engineering design purposes. This Paper summarizes some of the basic information upon which such simplifying assumptions can be made. A simple empirical failure criterion is presented and its application in enginecring design is illustratcd by means of a number of practical examples.

Des masses jointives de rochers comprennent des particules angulaires enchevêtrées ou des blocs de matière dure et cassante séparés par des surfaces discontinues enrobces ou non de matic̀res de moindre résistance. La résistance de masses rocheuses de ce genre dépend de la résistance des morceaux intacts et de leur liberté de mouvement, qui sont fonctions elles mêmes du nombre, de l'orientation, de l'écartement et de la résistance à la rupture au cisaillement des discontinuités. La compréhension complète de ce problème presente des difficultés considérables d'aspect théorique et expérimental, de sorte que des hypotheses simplificatrices sont nécessaires pour avoir une base raisonnable sur laquelle on peut estimer la résistance des masses jointives de rochers en vue de la construction. Cet article résume quelques-unes des données de base sur lesquelles de telles hypothèses simplificatrices peuvent être faites. Un critère de rupture empirique de nature très simple est donné, son application à la construction ètant illustrée au moyen d'un certain nombre d'exemples pratiques.

\section{INTRODUCTION}

The past twenty years have seen remarkable developments in the field of geotechnical engineering, particularly in the application of computers to the analysis of complex stress distribution and stability problems. There have also been important advances in the field of geotechnical equipment and instrumentation and in the

* Golder Associates, Vancouver. understanding of concepts such as the interaction between a concrete or steel structure and the soil foundation on which it is built or, in the case of a tunnel, the interaction between the rock mass surrounding the tunnel and the support system installed in the tunnel. Similarly, there have been significant advances in our ability to understand and to analyse the role of structural features such as joints, bedding planes and faults in controlling the stability of both surface and underground excavations.

In spite of these impressive advances, the geotechnical engineer is still faced with some areas of major uncertainty and one of these relates to the strength of jointed rock masses. This problem is summed up very well in a paper on rockfill materials by Marachi, Chan \& Seed (1972) when they say 'No stability analysis, regardless of how intricate and theoretically exact it may be, can be useful for design if an incorrect estimation of the shearing strength of the construction material has been made'. These authors go on to show that, although laboratory tests on rockfill are difficult and expensive because of the size of the equipment involved, there are techniques available to permit realistic and reliable evaluation of the shear strength of typical rockfill used for dam construction.

Unfortunately, this is not true for jointed rock masses where a realistic evaluation of shear strength presents formidable theoretical and experimental problems. However, since this question is of fundamental importance in almost all major designs involving foundations, slopes or underground excavations in rock, it is essential that such strength estimates be made and that these estimates should be as reliable as possible.

In this Paper the Author has attempted to summarize what is known about the strength of jointed rock masses, to deal with some of the theoretical concepts involved and to explore their limitations and to propose some simple empirical approaches which have been found useful in solving real engineering problems. Examples of such engineering problems are given.

\section{DEFINITION OF THF PRORI.EM}

Figure 1 summarizes the range of problems 


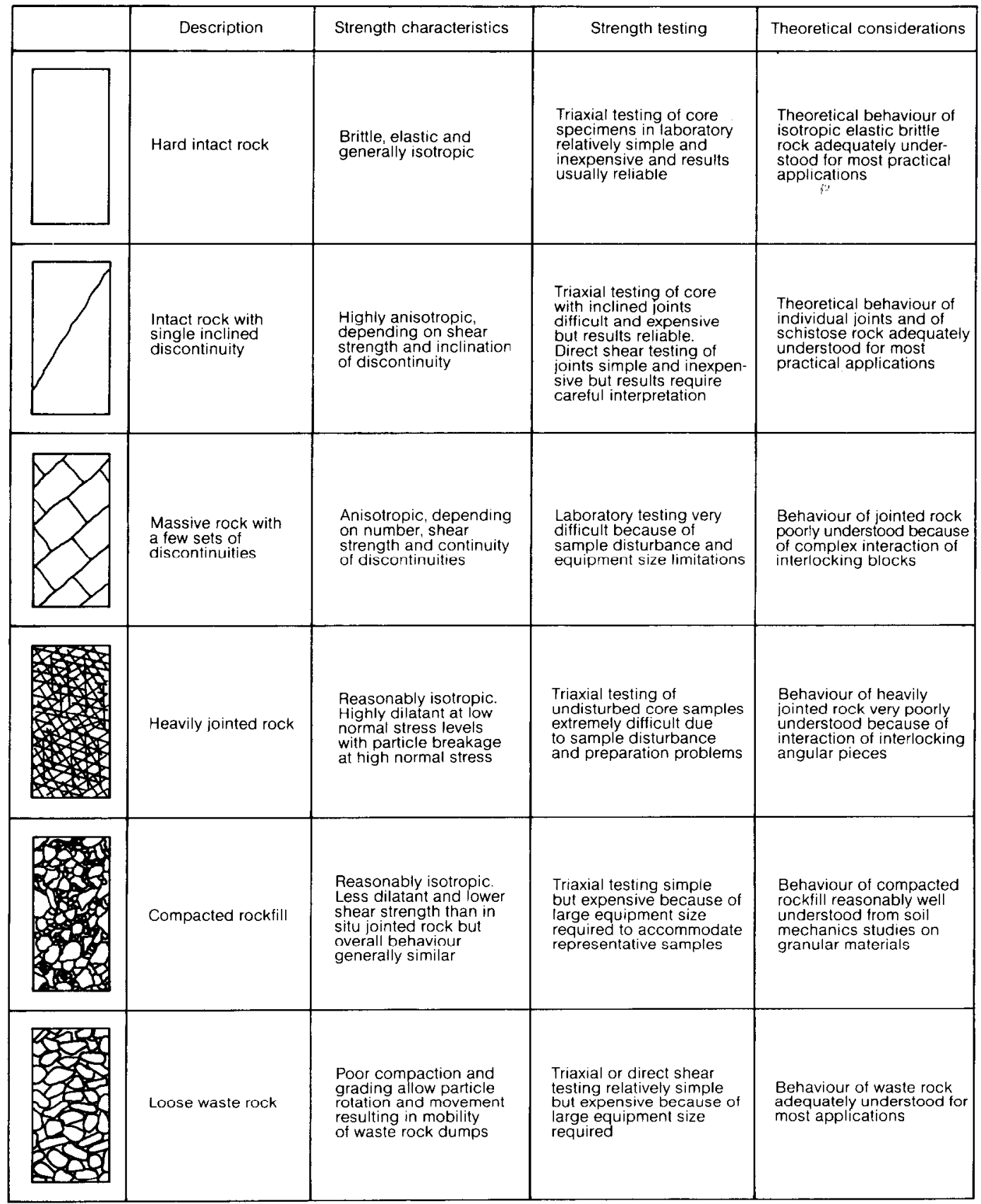

Fig. 1. Summary of range of rock mass characteristics 
considered. In order to understand the behaviour of jointed rock masses, it is necessary to start with the components which go together to make up the system-the intact rock material and the individual discontinuity surfaces. Depending on the number, orientation and nature of the discontinuities, the intact rock pieces will translate, rotate or crush in response to stresses imposed on the rock mass. Since there are a large number of possible combinations of block shapes and sizes, it is necessary to find behavioural trends which are common to all of these combinations. The establishment of such common trends is the most important objective of this Paper.

Before embarking upon a study of the individual components and of the system as a whole, it is necessary to set down some basic definitions.

Intact rock refers to the unfractured blocks which occur between structural discontinuities in a typical rock mass. These pieces may range from a few millimetres to several metres in size and their behaviour is generally elastic and isotropic. Their failure can be classified as brittle which implies a sudden reduction in strength when a limiting stress level is exceeded. In general, viscoelastic or timedependent behaviour such as creep is not considered to be significant unless one is dealing with evaporites such as salt or potash.

Joints are a particular type of geological discontinuity but the term tends to be used generically in rock mechanics and it usually covers all types of structural weakness with the exception of faults. Hence the term jointed rock mass may refer to an assemblage of blocks separated by joints, bedding planes, cleavage or any other type of structural weakness.

Strength, in the context of this Paper, refers to the maximum stress level which can be carried by a specimen. No attempt is made to relate this strength to the amount of strain which the specimen undergoes before failure nor is any consideration given to the post-peak behaviour or the relationship between peak and residual strength. It is recognized that these factors are important in certain engineering applications but such problems are beyond the scope of this Paper.

The presentation of rock strength data and its incorporation into a failure criterion depends on the preference of the individual and on the end use for which the criterion is intended. In dealing with slope stability problems where limit equilibrium methods of analyses are used, the most useful failure criterion is one which expresses the shear strength in tcrms of the cffective normal stress acting across a particular weakness plane or shear zone. The presentation which is most familiar to soil mechanics engineers is the Mohr failure envelope. On the other hand, when analysing the stability of underground excavations, the response of the rock to the principal stresses acting upon each element is of paramount interest. Consequently, a plot of triaxial test data in terms of the major principal stress at failure versus minimum principal stress or confining pressure is the most useful form of failure criterion for the underground excavation engineer. Other forms of failure criterion involving induced tensile strain, octahedral shear stress or energy considerations will not be dealt with.

Most of the discussion on failure criteria will be presented in terms of Mohr failure envelopes. With the Author's background being in underground excavation engineering the starting point for most of his studies is the triaxial test and the presentation of failure criteria in terms of principal stresses rather than shear and normal stresses. This starting point has an important bearing on the form of the empirical failure criterion presented.

\section{STRENGTH OF THE INTACT ROCK}

A vast amount of information on the strength of intact rock has been published during the past fifty years, and this was reviewed by the late Professor J. C. Jaeger in the eleventh Rankine lecture (1971).

In this context, one of the most significant steps was a suggestion by Murrell (1958) that the brittle fracture criterion proposed by Griffith $(1921,1925)$ could be applied to rock. Griffith postulated that, in brittle materials such as glass, fracture initiated when the tensile strength of the material is exceeded by stresses generated at the ends of microscopic flaws in the material. In rock, such flaws could be pre-existing cracks, grain boundaries or other discontinuities. Griffith's theory, summarized for rock mechanics applications by Hoek (1968), predicts a parabolic Mohr failure envelope defined by the equation

$$
\tau=2\left(\left|\sigma_{t}\right|\left(\left|\sigma_{t}\right|+\sigma^{\prime}\right)\right)^{1 / 2}
$$

where $\tau$ is the shear stress, $\sigma^{\prime}$ is the effective normal stress and $\sigma_{1}$ is the tensile strength of the material (note that tensile stresses are considered negative throughout this Paper).

Griffith's theory was originally derived for predominantly tensile stress fields. In applying this criterion to rock subjected to compressive stress conditions, it soon became obvious that the frictional strength of closed cracks has to be allowed for, and McClintock \& Walsh (1962) proposed a modification to Griffith's theory to account for these frictional forces. The Mohr failure envelope for the modificd Griffith theory is defined by the equation

$$
\tau=2\left|\sigma_{1}\right|+\sigma^{\prime} \operatorname{Tan} \phi^{\prime}
$$

where $\phi^{\prime}$ is the angle of friction on the crack 


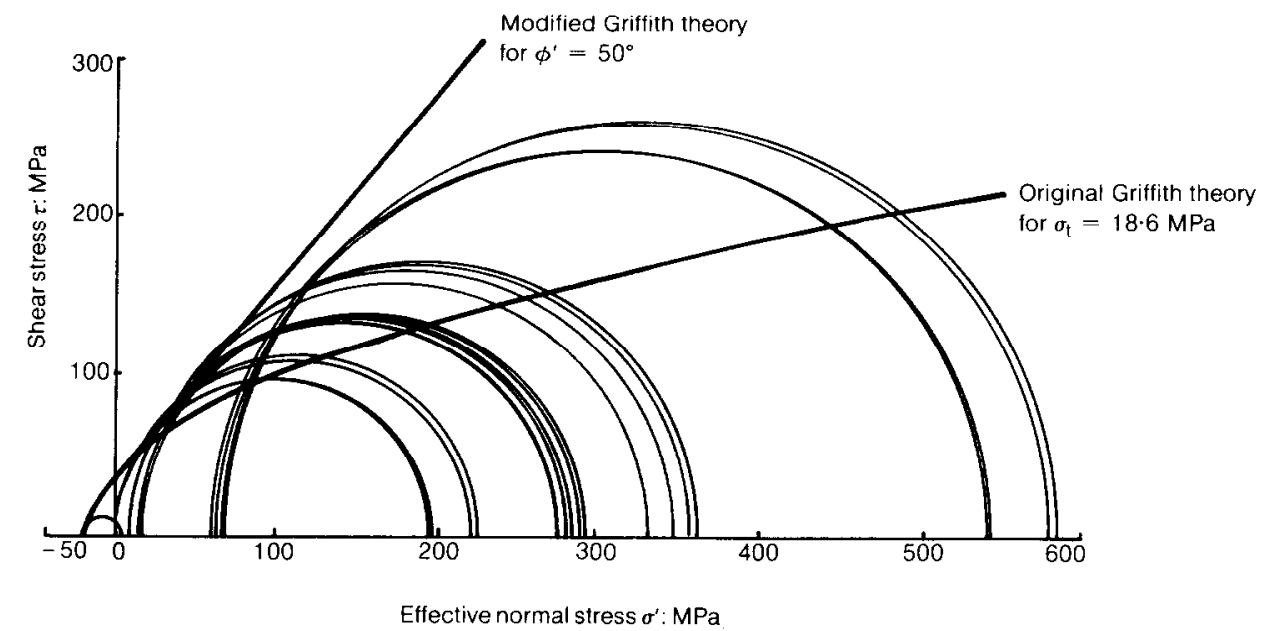

Fig. 2. Mohr circles for failure of specimens of quartzite tested by Hoek (1965). Envelopes included in the figure are calculated by means of the original and modified Griffith theories of brittle fracture initiation

surfaces. (Note, this equation is only valid for $\sigma^{\prime}>0$.)

Detailed studies of crack initiation and propagation by Hoek \& Bieniawski (1965) and Hoek (1968) showed that the original and modified Griffith theories are adequate for the prediction of fracture initiation in rocks but that they fail to describe fracture propagation and failure of a sample. Fig. 2 gives a set of Mohr circles for failure of specimens of quartzite tested triaxially (Hoek, 1965). Included in this figure are Mohr envelopes calculated by means of equations (1) and (2) for $\sigma_{\mathrm{t}}=18.6 \mathrm{MPa}$ and $\phi^{\prime}=50$ degrees. Neither of these curves can be considered acceptable envelopes to the Mohr circles representing failure of the quartzite under compressive stress conditions. In spite of the inadequacy of the original and modified Griffith theories in predicting the failure of intact rock specimens, a study of the mechanics of fracture initiation and of the shape of the Mohr envelopes predicted by these theories was a useful starting point in deriving the empirical failure criterion.

Jaeger (1971), in discussing failure criteria for rock, comments that 'Griffith theory has proved extraordinarily useful as a mathematical model for studying the effect of cracks on rock, but it is essentially only a mathematical model; on the microscopic scale rocks consist of an aggregate of anisotropic crystals of different mechanical properties and it is these and their grain boundaries which determine the microscopic behaviour'.

Recognition of the difficulty involved in developing a mathematical model which adequately predicts fracture propagation and failure in rock led a number of authors to propose empirical relationships between principal stresses or between shear and normal stresses at failure. Murrell (1965), Hoek (1968), Hobbs (1970) and Bieniawski (1974a) all proposed different forms of empirical criteria. The failure criterion on which the remainder of this Paper is based was presented by Hoek \& Brown (1980a, 1980b) and resulted from their efforts to produce an acceptable failure criterion for the design of underground excavations in rock.

\section{AN EMPIRICAL FAILURE CRITERION FOR ROCK}

In developing their empirical failure criterion, Hoek \& Brown (1980a) attempted to satisfy the following conditions

(a) The failure criterion should give good agreement with experimentally determined rock strength values.

(b) The failure criterion should be expressed by mathematically simple equations based, to the maximum extent possible, upon dimensionless parameters.

(c) The failure criterion should offer the possibility of extension to deal with anisotropic failure and the failure of jointed rock masses.

The studies on fracture initiation and propagation suggested that the parabolic Mohr envelope predicted by the original Griffith theory adequately describes both fracture initiation and failure of brittle materials under conditions where the effective normal stress acting across a preexisting crack is tensile (negative). This is because fracture propagation follows very quickly upon 

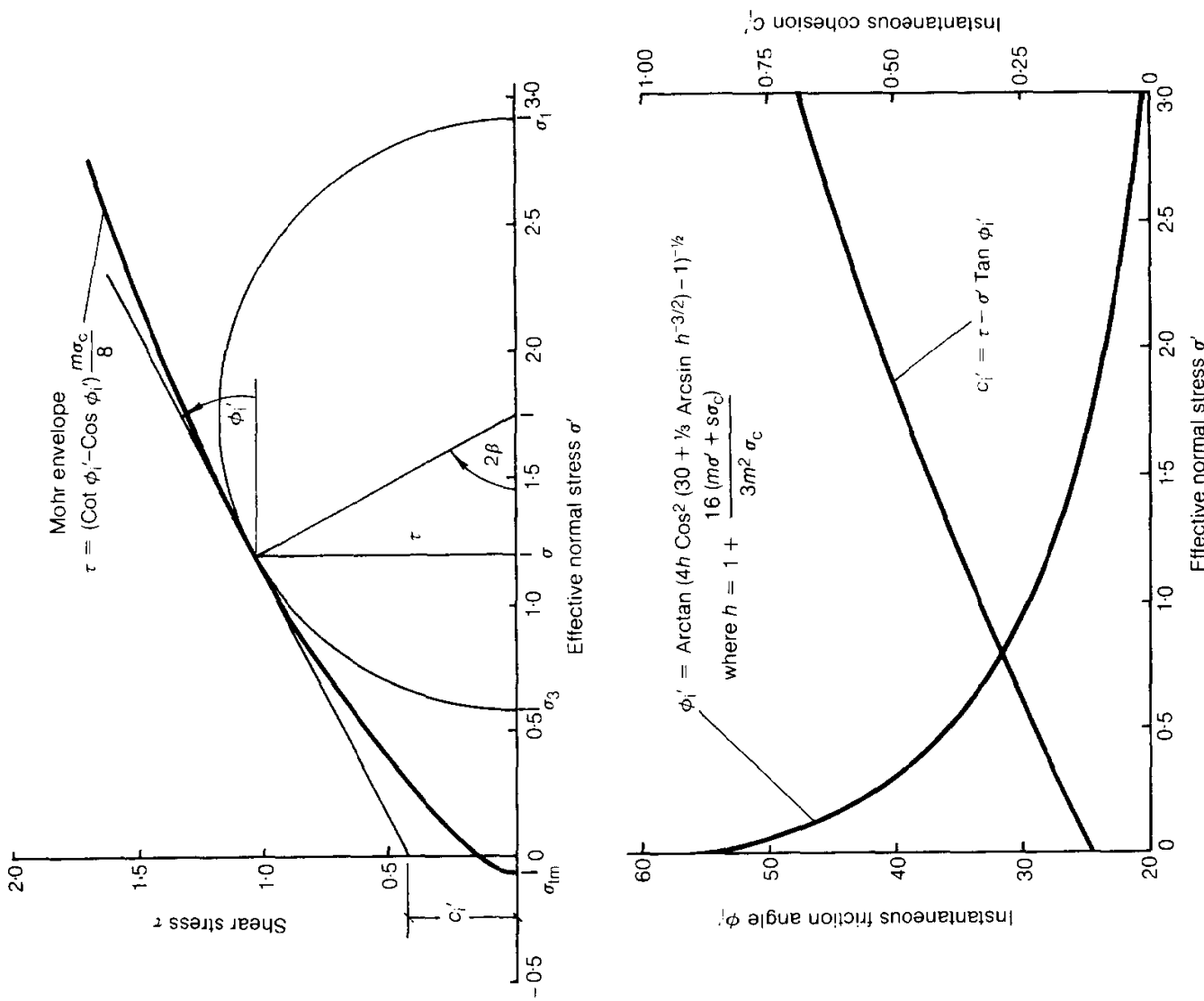

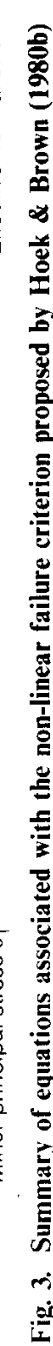


fracture initiation under tensile stress conditions, and hence fracture initiation and failure of the specimen are practically indistinguishable.

Figure 2 shows that, when the effective normal stress is compressive (positive), the envelope to the Mohr circles tends to be curvilinear, but not to the extent predicted by the original Griffith theory.

Based upon these observations, Hoek \& Brown (1980a) experimented with a number of distorted parabolic curves to find one which gave good coincidence with the original Griffith theory for tensile effective normal stresses, and which fitted the observed failure conditions for brittle rocks subjected to compressive stress conditions.

The process used by Hoek \& Brown in deriving their empirical failure criterion was one of pure trial and error. Apart from the conceptual starting point provided by Griffith theory, there is no fundamental relationship between the empirical constants included in the criterion and any physical characteristics of the rock. The justification for choosing this particular criterion over the numerous alternatives lies in the adequacy of its predictions of observed rock fracture behaviour, and the convenience of its application to a range of typical engineering problems.

The Author's background in designing underground excavations in rock resulted in the decision to present the failure criterion in terms of the major and minor principal stresses at failure. The empirical equation defining the relationship between these stresses is

$$
\sigma_{1}{ }^{\prime}=\sigma_{3}{ }^{\prime}+\left(m \sigma_{\mathrm{c}} \sigma_{3}{ }^{\prime}+s \sigma_{\mathrm{c}}{ }^{2}\right)^{1 / 2}
$$

where $\sigma_{1}{ }^{\prime}$ is the major principal effective stress at failure, $\sigma_{3}{ }^{\prime}$ is the minor principal effective stress or, in the case of a triaxial test, the confining pressure, $\sigma_{\mathrm{c}}$ is the uniaxial compressive strength of the intact rock material from which the rock mass is made up, and $m$ and $s$ are empirical constants.

The constant $m$ always has a finite positive value which ranges from about 0.001 for highly disturbed rock masses, to about 25 for hard intact rock. The value of the constant $s$ ranges from 0 for jointed masses, to 1 for intact rock material.

Substitution of $\sigma_{3}{ }^{\prime}=0$ into equation (3) gives the unconfined compressive strength of a rock mass as

$$
\sigma_{1}^{\prime}=\sigma_{\mathrm{c}}-\left(s \sigma_{\mathrm{c}}{ }^{2}\right)^{1 / 2}
$$

Similarly, substitution of $\sigma_{1}{ }^{\prime}=0$ in equation (3), and solution of the resulting quadratic equation for $\sigma_{3}{ }^{\prime}$, gives the uniaxial tensile strength of a rock mass as

$$
\sigma_{3}{ }^{\prime}=\sigma_{\mathrm{t}}=\frac{1}{2} \sigma_{\mathrm{c}}\left(m-\left(m^{2}+4 s\right)^{1 / 2}\right)
$$

The physical significance of equations (3)-(5) is illustrated in the plot of $\sigma_{1}{ }^{\prime}$ against $\sigma_{3}{ }^{\prime}$ given in Fig. 3.
While equation (3) is very useful in designing underground excavations, where the response of individual rock elements to in situ and induced stresses is important, it is of limited value in designing rock slopes where the shear strength of a failure surface under specified effective normal stress conditions is required. The Mohr failure envelope corresponding to the empirical failure criterion defined by equation (3) was derived by $\mathrm{Dr}$ J. Bray of Imperial College and is given by

$$
\tau=\left(\operatorname{Cot} \phi_{\mathrm{i}}{ }^{\prime}-\operatorname{Cos} \phi_{\mathrm{i}}{ }^{\prime}\right) \frac{m \sigma_{\mathrm{c}}}{8}
$$

where $\tau$ is the shear stress at failure, $\phi_{\mathrm{i}}{ }^{\prime}$ is the instantaneous friction angle at the given values of $\tau$ and $\sigma^{\prime}$-i.e. the inclination of the tangent to the Mohr failure envelope at the point $\left(\sigma^{\prime}, \tau\right)$ as shown in Fig. 3.

The value of the instantaneous friction angle $\phi_{i}^{\prime}$ is given by

$$
\begin{aligned}
\phi_{\mathrm{i}}{ }^{\prime}= & \operatorname{Arctan}\left(4 h \operatorname{Cos}^{2}(30\right. \\
& \left.\left.+\frac{1}{3} \operatorname{Arcsin} h^{-3 / 2}\right)-1\right)^{-1 / 2}
\end{aligned}
$$

where

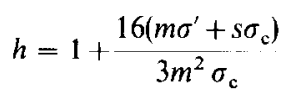

and $\sigma^{\prime}$ is the effective normal stress

The instantaneous cohesive strength $c_{\mathrm{i}}{ }^{\prime}$, shown in Fig. 3, is given by

$$
c_{\mathrm{i}}^{\prime}=\tau-\sigma^{\prime} \operatorname{Tan} \phi_{\mathrm{i}}^{\prime}
$$

From the Mohr circle construction given in Fig. 3 , the failure plane inclination $\beta$ is given by

$$
\beta=45-\frac{1}{2} \phi_{\mathrm{i}}{ }^{\prime}
$$

An alternative expression for the failure plane inclination, in terms of the principal stresses $\sigma_{1}{ }^{\prime}$ and $\sigma_{3}{ }^{\prime}$, was derived by Hoek \& Brown (1980a):

$$
\beta=\frac{1}{2} \operatorname{Arcsin} \frac{\tau_{m}}{\tau_{m}+m \sigma_{c} / 8}\left(1+m \sigma_{c} / 4 \tau_{m}\right)^{1 / 2}
$$

where $\tau_{m}=\frac{1}{2}\left(\sigma_{1}{ }^{\prime}-\sigma_{3}{ }^{\prime}\right)$.

\section{CIIARACTERISTICS OF EMPIRICAL CRITERION}

The empirical failure criterion presented in the preceding section contains three constants; $m, s$ and $\sigma_{\mathrm{c}}$. The significance of each of these will be discussed in turn later.

Constants $m$ and $s$ are both dimensionless and are very approximately analogous to the angle of friction, $\phi^{\prime}$, and the cohesive strength, $c^{\prime}$, of the conventional Mohr-Coulomb failure criterion.

Figure 4 illustrates the influence of different values of the constant $m$ on the Mohr failure envelope for intact rock. In plotting these curves, 

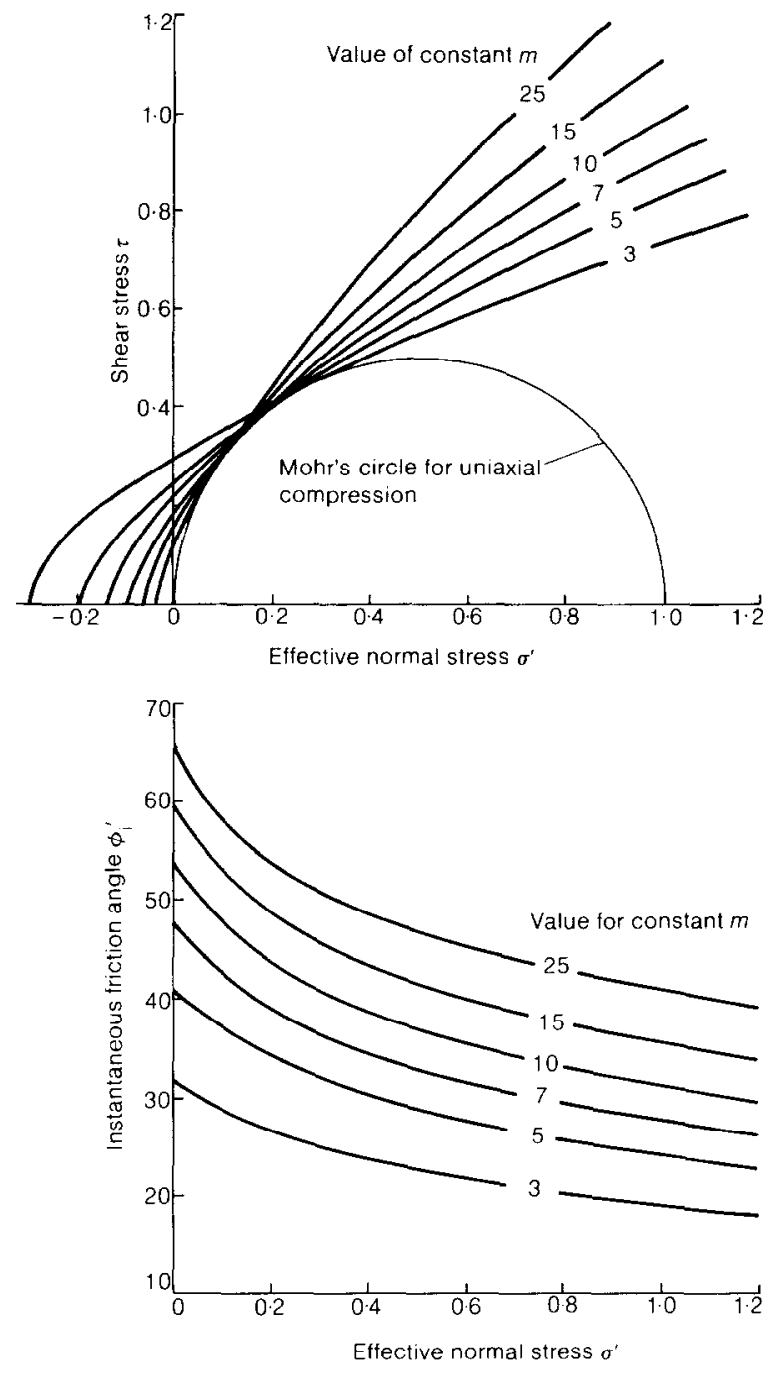

Fig. 4. Influence of the value of the constant $m$ on the shape of the Mohr failure envelope and on the instantaneous friction angle at different effective normal stress levels

the values of both $s$ and $\sigma_{\mathrm{c}}$ are assumed equal to unity.

Large values of $m$, in the order of 15-25, give steeply inclined Mohr envelopes and high instantaneous friction angles at low effective normal stress levels. These large $m$ values tend to be àssociated with brittle igneous and metamorphic rocks such as andesites, gneisses and granites. Lower $m$ values, in the order of 3-7, give lower instantaneous friction angles and tend to be associated with more ductile carbonate rocks such as limestone and dolomite.

The influence of the value of the constant $s$ on the shape of the Mohr failure envelope and on the instantaneous friction angle at different effective normal stress levels is illustrated in Fig. 5. The maximum value of $s$ is 1 , and this applies to intact rock specimens which have a finite tensile strength (defined by equation (5)). The minimum value of $s$ is zero, and this applies to heavily jointed or broken rock in which the tensile strength has been reduced to zero and where the rock mass has zero cohesive strength when the effective normal stress is zero.

The third constant, $\sigma_{\mathrm{c}}$, the uniaxial compressive strength of the intact rock material, has the dimensions of stress. This constant was chosen after very careful consideration of available rock 
strength data. The unconfined compressive strength is probably the most widely quoted constant in rock mechanics, and it is likely that an estimate of this strength will be available in cases where no other rock strength data are available. Consequently, it was decided that the uniaxial compressive strength $\sigma_{\mathrm{c}}$ would be adopted as the basic unit of measurement in the empirical failure criterion.

The failure criterion defined by equation (3) can be made entirely dimensionless by dividing both sides by the uniaxial compressive strength

$$
\sigma_{1}{ }^{\prime} / \sigma_{\mathrm{c}}=\sigma_{3}{ }^{\prime} / \sigma_{\mathrm{c}}+\left(m \sigma_{3}{ }^{\prime} / \sigma_{\mathrm{c}}+s\right)^{1 / 2}
$$

This formulation, which can also be achieved by simply putting $\sigma_{\mathrm{c}}=1$ in equation (3), is very useful when comparing the shapc of Mohr failure envelopes for different rock materials.

A procedure for the statistical determination of the values of the constants $m, s$ and $\sigma_{\mathfrak{c}}$ from
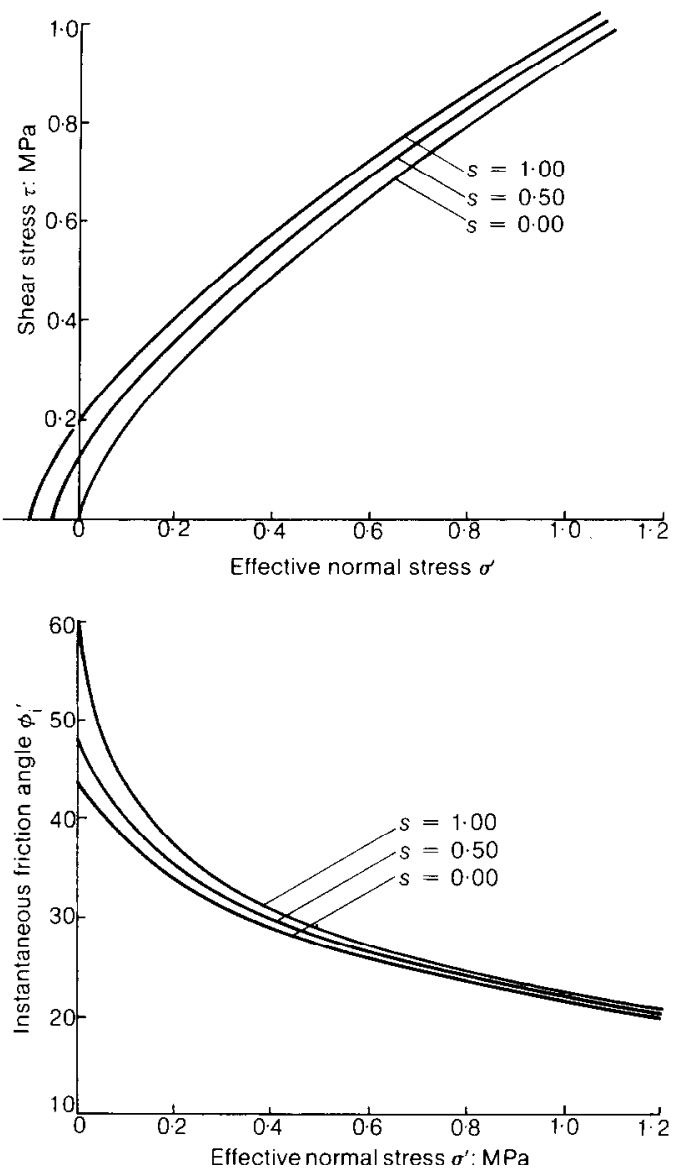

Fig. 5. Influence of the value of the constant $s$ on the shape of the Mohr failure envelope and on the instantaneous friction angle at different effective normal stress levels experimental data is given in Appendix 1.

\section{TRIAXIAL DATA FOR INTACT ROCK}

Hoek \& Brown (1980a) analysed published data from several hundred triaxial tests on intact rock specimens and found some useful trends. These trends will be discussed in relationship to the two sets of data plotted as Mohr failure circles in Fig. 6. The sources of the triaxial data plotted in Fig. 6 are given in Table 1.

Figure 6(a) gives Mohr failure envelopes for five different granites from the USA and UK. Tests on these granites were carried out in five different laboratories using different triaxial equipment. In spite of these differences, the failure characteristics of these granites follow a remarkably consistent pattern, and the Mohr failure envelope predicted by equations (6) and (7) for $\sigma_{\mathrm{c}}=1, \quad m=29 \cdot 2$ and $s=1$ fits all of these Mohr circles very well. Table 1 shows that a correlation coefficient of 0.99 was obtained by statistically fitting the empirical failure criterion defined by equation (3) to all of the granite strength data.

The term granite defines a group of igneous rocks having very similar mineral composition, grain size and angularity, and hence the failure characteristics exhibited by these rocks are very similar, irrespective of the source of the granite. The trend illustrated in Fig. 6(a) has very important practical implications, since it suggests that it should be possible, given a description of the rock and an estimate of its uniaxial compressive strength, to predict its Mohr failure envelope with a relatively high degree of confidence. This is particularly important in early conceptual or feasibility studies where the amount of reliable laboratory data is very limited.

In contrast to the trends illustrated in Fig. 6(a) for granite, the plot given in Fig. 6(b) for limestone is less convincing. In this case, eleven different limestones, tested in three different laboratories, have been included in the plot. Table 1 shows that the values of the constant $m$, derived from statistical analyses of the test data, vary from $3 \cdot 2$ to 141 , and that the correlation coefficient for the complete data set is only $0 \cdot 68$.

The scatter of the data included in Fig. 6(b) is attributed to the fact that the generic term limestone applies to a range of carbonate rocks formed by deposition of a variety of organic and inorganic materials. Consequently, mineral composition, grain size and shape, and the nature of cementing materials between the grains, will vary from one limestone to another.

Comparison of the two plots given in Fig. 6 suggests that the empirical failure criterion presented here gives a useful indication of the general trend of the Mohr failure envelope for 


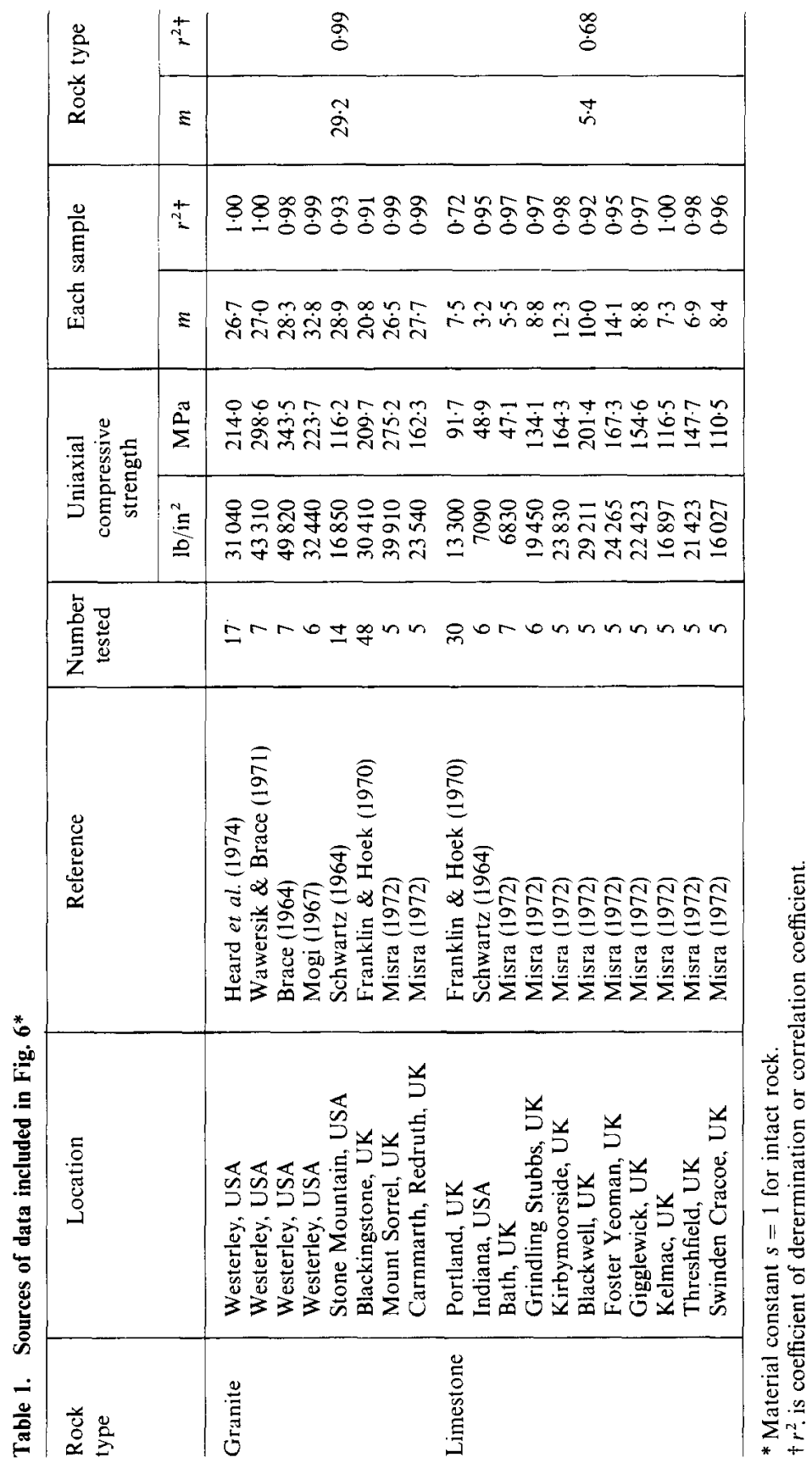




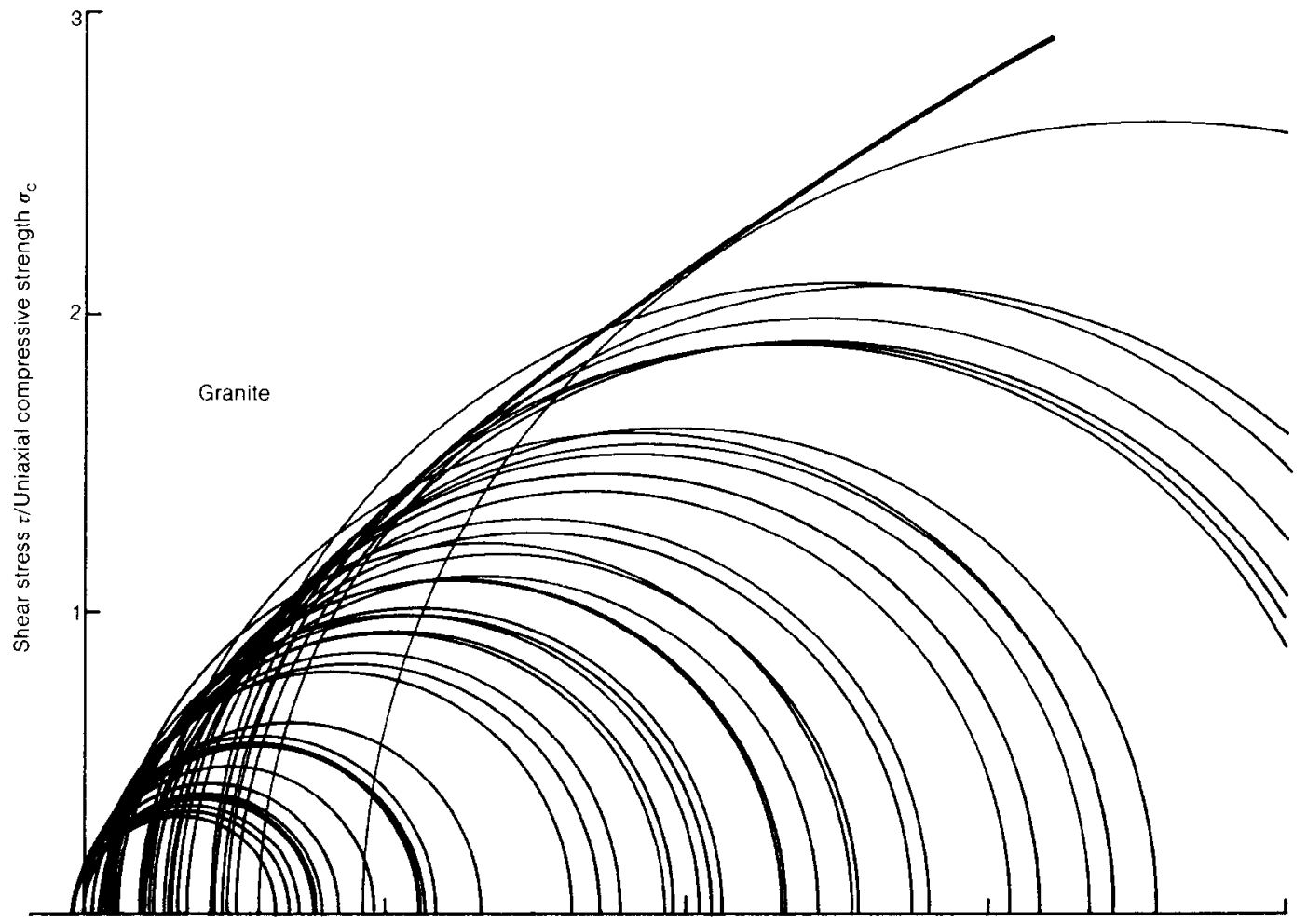

(a)

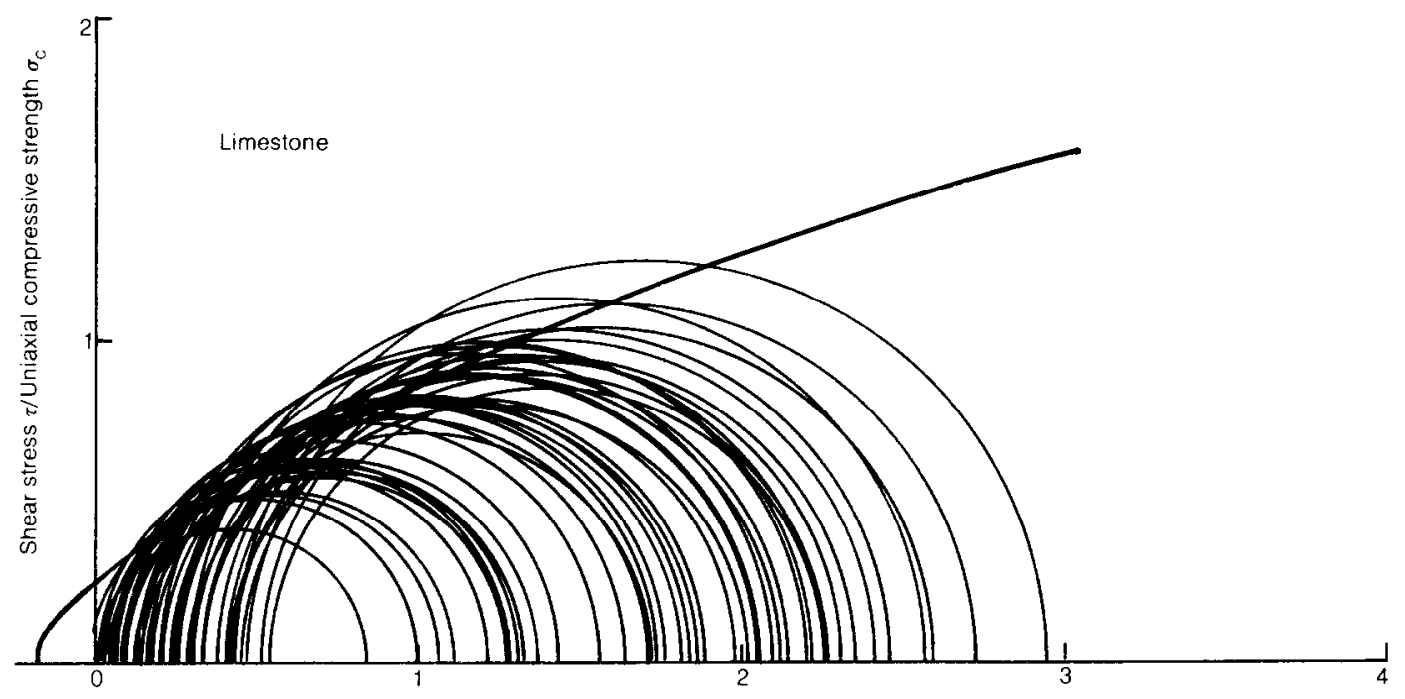

Effective normal stress $\sigma^{\prime} /$ Uniaxial compressive strength $\sigma_{\mathrm{C}}$

(b)

Fig. 6. Mohr failure circles for published triaxial test data for intact samples of (a) granite and (b) limestone 
different rock types. The accuracy of each prediction will depend on the adequacy of the description of the particular rock under consideration. In comparing the granites and limestones included in Fig. 6, there would obviously be a higher priority in carrying out confirmatory laboratory tests on the limestone than on the granite.

Hoek \& Brown (1980a) found that there were definite trends which emerged from the statistical fitting of their empirical failure criterion (equation (3)) to published triaxial data. For intact rock (for which $s=1$ ), these trends are characterized by the value of the constant $m$ which, as illustrated in Fig. 4, defines the shape of the Mohr failure envelope. The trends suggested by Hoek \& Brown (1980a) are

(a) Carbonate rocks with well developed crystal cleavage (dolomite, limestone and marble); $m=7$

(b) Lithified argillaceous rocks [mudstone, shale and slate (normal to cleavage)]; $m=10$

(c) Arenaceous rocks with strong crystals and poorly developed crystal cleavage (sandstone and quartzite); $m=15$

(d) Fine grained polyminerallic igneous crystalline rocks (andesite, dolerite, diabase and rhyotite); $m=17$

(e) Course grained polyminerallic igneous and metamorphic rocks (amphibolite, gabbro, gneiss, granite, norite and granodiorite); $m=25$

These trends will be utilized later when the estimation of the strength of the jointed rock masses is discussed.

The fitting of the empirical failure criterion defined by equation (3) to a particular set of triaxial data is illustrated in Fig. 7. The Mohr circles plotted were obtained by Bishop \& Garga (1969) from a series of carefully performed triaxial tests on undisturbed samples of London clay (Bishop, Webb \& Lewin, 1965). The Mohr envelope plotted in Fig. 7 was determined from a statistical analysis of Bishop \& Garga's data (using the technique described in Appendix 1), and the values of the constants are $\sigma_{\mathrm{c}}=211.8 \mathrm{kPa}$, $m=6.475$ and $s=1$. The correlation coefficient for the fit of the empirical criterion to the experimental data is 0.98 .

This example was chosen for its curiosity value rather than its practical significance, and because of the strong association between the British Geotechnical Society and previous Rankine lecturers and London clay. The example does serve to illustrate the importance of limiting the use of the empirical failure criterion to a low effective normal stress range. Tests on London clay at higher effective normal stress levels by Bishop et al. (1965) gave approximately linear Mohr failure envelopes with friction angles of about $11^{\circ}$.

As a rough rule of thumb, when analysing intact rock behaviour, the Author limits the use of the empirical failure criterion to a maximum effective normal stress level equal to the unconfined compressive strength of the material. This question is examined later in a discussion on brittle-ductile transition in intact rock.

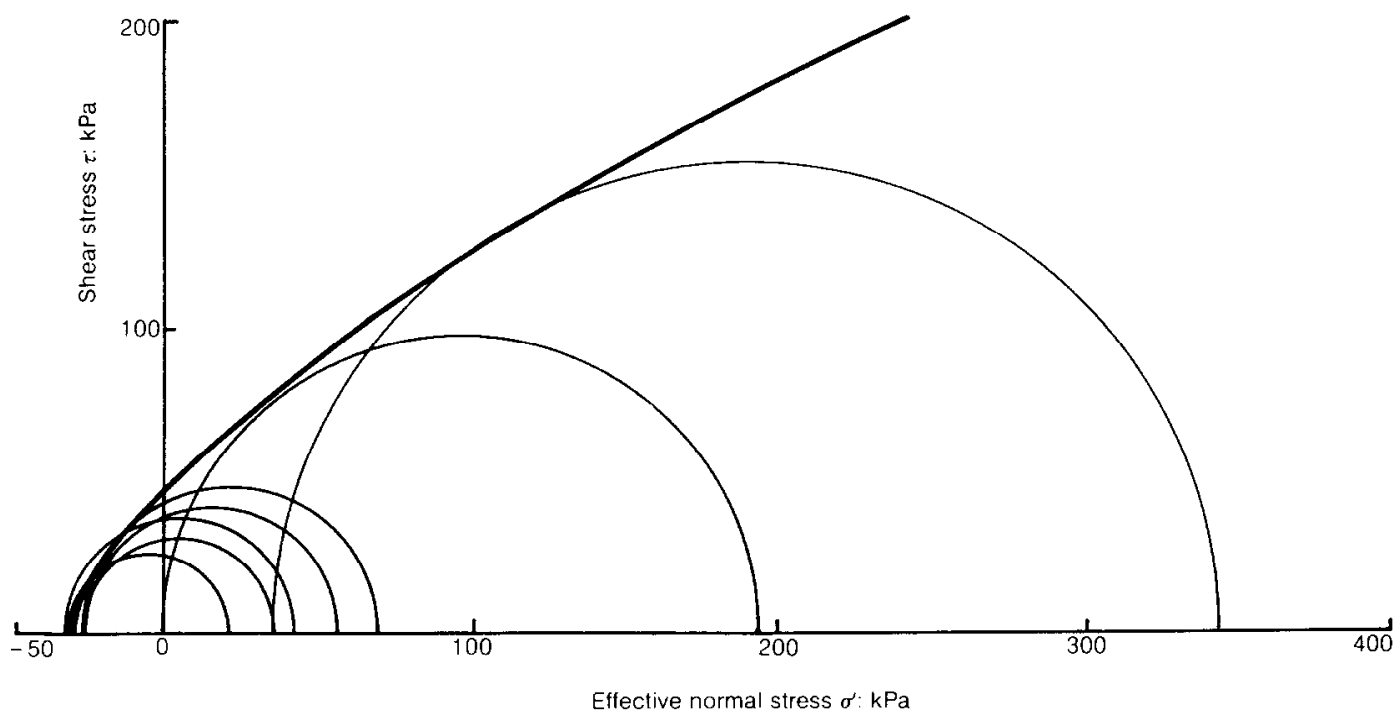

Fig. 7. Mohr failure envelope for drained triaxial tests at very low normal stress levels carried out by Bishop \& Garga (1969) on undisturbed samples of London clay 
Table 2. Observed and predicted failure plane inclination for Tennessee marble (Wawersik, 1968)

\begin{tabular}{|c|c|c|c|}
\hline $\begin{array}{l}\text { Confining } \\
\text { pressure: } \mathrm{MPa}\end{array}$ & $\begin{array}{c}\text { Axial } \\
\text { strength: } \mathrm{MPa}\end{array}$ & $\begin{array}{c}\text { Observed } \\
\text { fracture angle }\end{array}$ & $\begin{array}{c}\text { Predicted } \\
\text { fracture angle }\end{array}$ \\
\hline 0 & 134.48 & $18 \cdot 0$ & $26 \cdot 61$ \\
\hline 3.45 & 143.45 & $23-4$ & $27 \cdot 0$ \\
\hline 6.90 & $160 \cdot 00$ & $24 \cdot 8$ & $27 \cdot 7$ \\
\hline $13 \cdot 79$ & $186 \cdot 21$ & $31 \cdot 7$ & $28 \cdot 7$ \\
\hline $20 \cdot 69$ & $201 \cdot 38$ & $35 \cdot 1$ & $29 \cdot 1$ \\
\hline 27.59 & $220 \cdot 00$ & $36 \cdot 3$ & 29.7 \\
\hline $34-48$ & 251.03 & $37 \cdot 8$ & $30 \cdot 6$ \\
\hline $48 \cdot 28$ & $286 \cdot 21$ & $38 \cdot 8$ & 31.4 \\
\hline
\end{tabular}

\section{ASSUMPTIONS INCLUDED IN EMPIRICAL FAILURE CRITERION}

A number of simplifying assumptions have been made in deriving the empirical failure criterion, and it is necessary to discuss these assumptions before extending the criterion to deal with jointed rock masses.

\section{Effective stress}

Throughout this discussion, it is assumed that the empirical failure criterion is valid for effective stress conditions. In other words, the effective stress $\sigma^{\prime}$ used in equations (7) and (8) is obtained from $\sigma^{\prime}=\sigma-u$, where $\sigma$ is the applied normal stress and $u$ is the pore or joint water pressure in the rock. In spite of some controversy on this subject, discussed by Jaeger \& Cook (1969), Brace \& Martin (1968) demonstrate that the effective stress concept appears to be valid in intact rocks of extremely low permeability, provided that loading rates are sufficiently low to permit pore pressures to equalize. For porous rocks such as sandstone, normal laboratory loading rates will generally satisfy effective stress conditions (Handin, Hager, Friedman \& Feather, 1963) and there is no reason to suppose that they will not apply in the case of jointed rocks.

\section{Influence of pore fluid on strength}

In addition to the influence of pore pressure on strength, it is generally accepted that the pore fluid itself can have a significant influence on rock strength. For example, Colback \& Wiid (1965) and Broch (1974) showed that the unconfined compressive strength of quartzitic shale, quartzdiorite, gabbro and gneiss can be reduced by as much as two by saturation in water as compared with oven dried specimens. Analyses of their results suggest that this reduction takes place in the unconfined compressive strength $\sigma_{\mathrm{c}}$ and not in the constant $m$ of the empirical failure criterion.

It is important, in testing rock materials or in comparing data from rock strength tests, that the moisture content of all specimens be kept within a narrow range. In the Author's own experience in testing samples of shale which had been left standing on the laboratory shelf for varying periods of time, the very large amount of scatter in strength data was almost eliminated by storing the specimens in a concrete curing room to bring them close to saturation before testing. Obviously, in testing rocks for a particular practical application, the specimens should be tested as close to in situ moisture content as possible.

\section{Influence of loading rate}

With the exception of effective stress tests on very low porosity materials (e.g. Brace \& Martin, 1968), or tests on viscoelastic materials such as salt or potash, it is generally assumed that the influence of loading rate is insignificant when dealing with rock. While this may be an oversimplification, the Author believes that it is sufficiently accurate for most practical applications.

\section{Influence of specimen size}

Hoek \& Brown (1980a) have analysed the influence of specimen size on the results of strength tests on the intact rock samples. They found that the influence of specimen size can be approximated by the relationship

$$
\sigma_{\mathrm{c}}=\sigma_{\mathrm{c} 50}(50 / d)^{0 \cdot 18}
$$

where $\sigma_{\mathrm{c}}$ is the unconfined compressive strength, $d$ is the diameter of the specimen in millimetres and $\sigma_{\mathrm{c} 50}$ is the unconfined compressive strength of a $50 \mathrm{~mm}$ diameter specimen of the same matcrial.

In the case of jointed rocks, the influence of size is controlled by the relationship between the spacing of joints and the size of the sample. This problem is dealt with later in the discussion on jointed rock masses.

\section{Influence of intermediate principal stress}

In deriving the empirical failure criterion presented here, Hoek \& Brown (1980a) assumed 


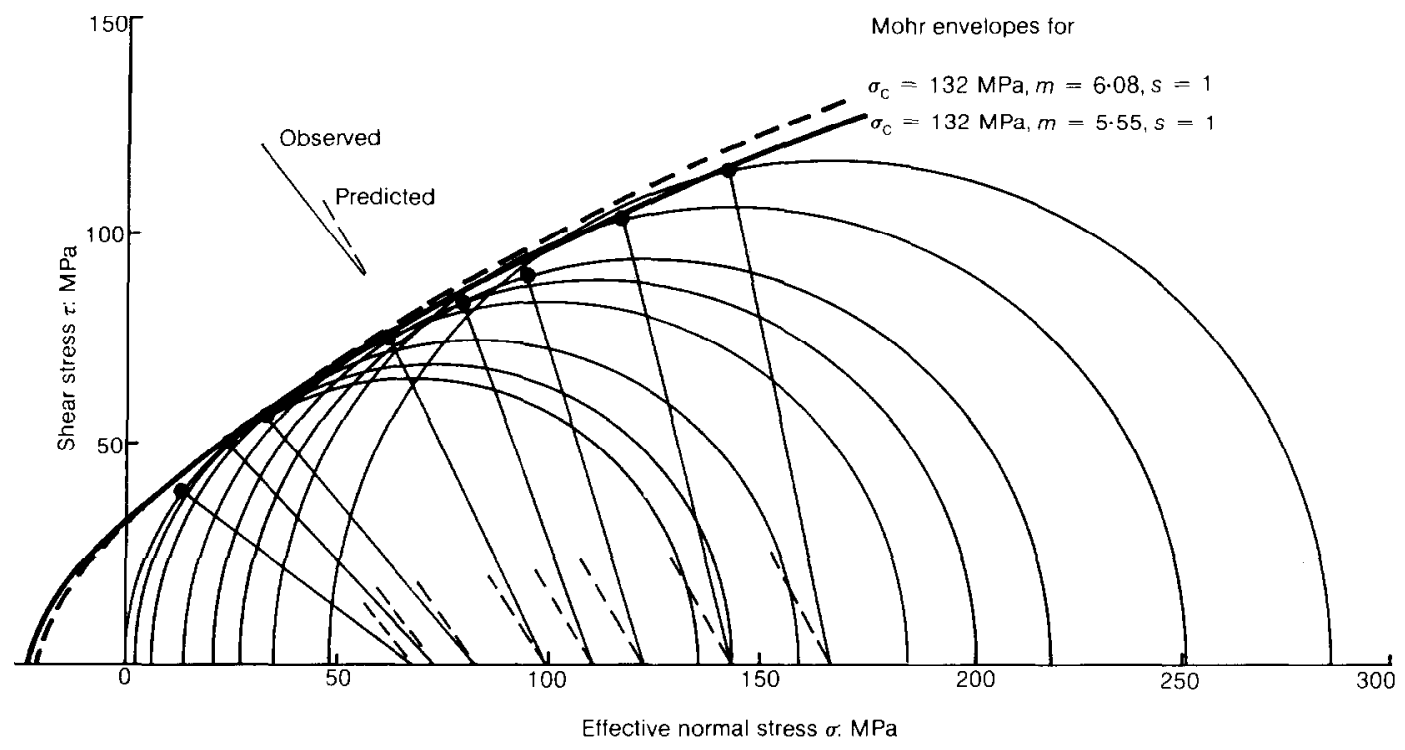

Fig. 8. Plnt of Mohr failure circles for Tennessee marble tested by Wawersik (1968) giving comparison between predicted and observed failure plane inclinations

that the failure process is controlled by the major and minor principal stresses $\sigma_{1}{ }^{\prime}$ and $\sigma_{3}{ }^{\prime}$, and that the intermediate principal stress $\sigma_{2}^{\prime}$ has no significant influence upon this process. This is almost certainly an over-simplification, but there appears to be sufficient evidence (reviewed by Jaeger \& Cook, 1969) to suggest that the influence of the intermediate principal stress can be ignored without introducing unacceptably large errors.

\section{Failure surface inclination}

The inclination of an induced failure plane in an intact rock specimen is given by equations (9) or (10). This inclination is measured from the direction of the maximum principal stress $\sigma_{1}{ }^{\prime}$, as illustrated in Fig. 3.

The results of a series of triaxial tests by Wawersik (1968) on Tennessee marble are listed in Table 2, and plotted as Mohr circles in Fig. 8. Also listed in Table 2 and plotted in Fig. 8, are observed failure plane inclinations.

A statistical analysis of the triaxial test data gives the following constants: $\sigma_{c}=132 \mathrm{MPa}$, $m=6.08, s=1$, with a correlation coefficient $r^{2}=0.99$. The Mohr envelope defined by these constants is plotted as a dashed curve in Fig. 8.

The predicted fracture angles listed in Table 2 have been calculated for $\sigma_{\mathrm{c}}=132 \mathrm{MPa}$ and $m=6.08$ by means of equation (10), and there are significant differences between observed and predicted fracture angles.

However, a Mohr envelope fitted through the shear stress $(\tau)$ and effective normal stress $\left(\sigma^{\prime}\right)$ points defined by construction (using the Mohr circles), gives a value of $m=5.55$ for $\sigma_{\mathrm{c}}=132 \mathrm{MPa}$ and $s=1$. The resulting Mohr envelope, plotted as a full linc in Fig. 8, is not significantly different from the Mohr envelope determined by analysis of the principal stresses.

These findings are consistent with the Author's own experience in rock testing. The fracture angle is usually very difficult to define, and is sometimes obscured altogether. This is hecause, as discussed earlier, the fracture process is complicated and does not always follow a clearly defined path. When the failure plane is visible, the inclination of this plane cannot be determined to better than $\pm 5^{\circ}$. In contrast, the failure stresses determined from a carefully conducted set of triaxial tests are usually very clearly grouped, and the pattern of Mohr circles plotted in Fig. 8 is not unusual in intact rock testing.

To conclude, the failure plane inclinations predicted by equations (9) or (10) should be regarded as approximate only, and that, in many rocks, no clearly defined failure surfaces will be visible.

\section{Brittle-ductile transition}

The results of a series of triaxial tests carried out by Schwartz (1964) on intact specimens of Indiana limestone are plotted in Fig. 9. A transition from brittle to ductile behaviour appears to occur at a principal stress ratio of approximately $\sigma_{1}{ }^{\prime} / \sigma_{3}{ }^{\prime}=4 \cdot 3$.

A study of the failure characteristics of a number 


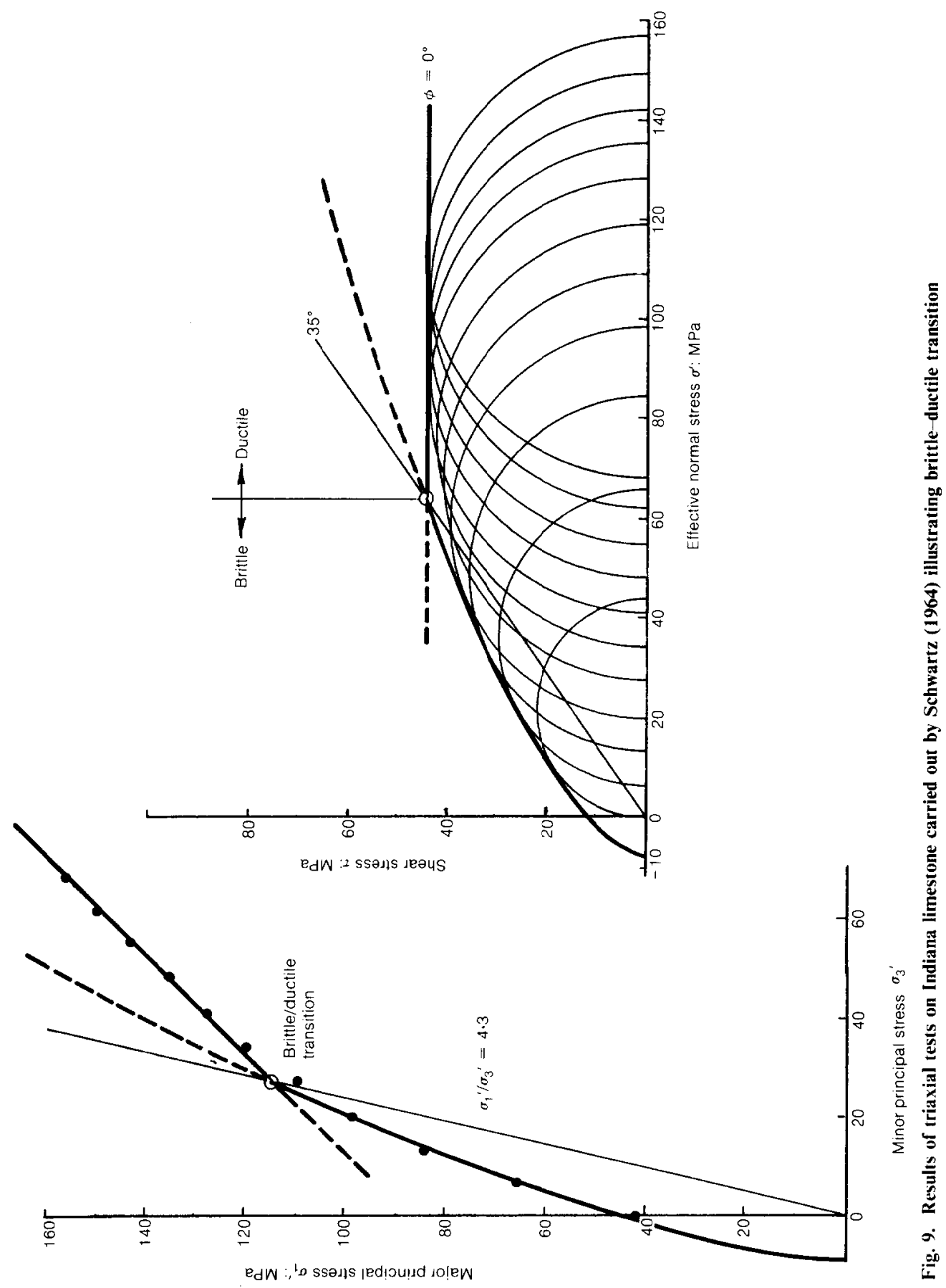




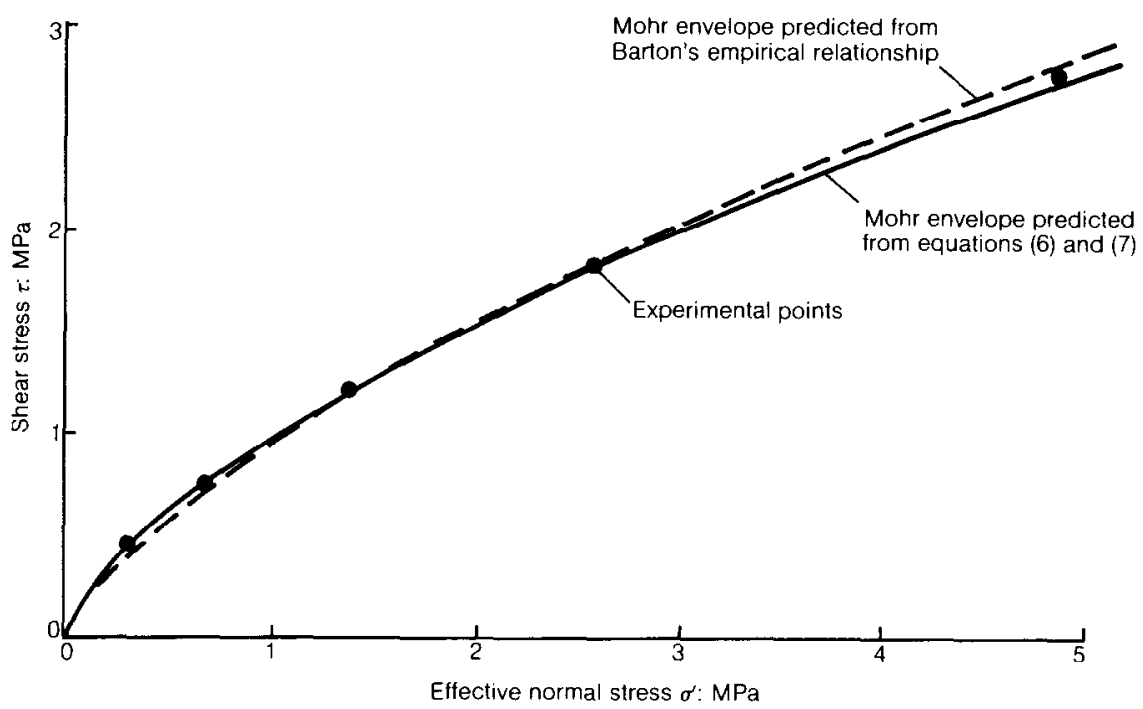

Fig. 10. Results of direct shear tests on moderately weathered greywacke, tested by Martin \& Miller (1974), compared with empirical failure envelopes

of rocks by Mogi (1966) led him to conclude that the brittle-ductile transition for most rocks occurs at an average principal stress ratio $\sigma_{1}{ }^{\prime} / \sigma_{3}{ }^{\prime}=3 \cdot 4$.

Examination of the results plotted in Fig. 9, and of similar results plotted by Mogi, shows that there is room for a wide variety of interpretations of the critical principal stress ratio, depending on the curve fitting procedure employed and the choice of the actual brittle-ductile transition point. The range of possible values of $\sigma_{1}{ }^{\prime} / \sigma_{3}{ }^{\prime}$ appears to lie between 3 and 5 .

A rough rule of thumb used by the Author is that the confining pressure $\sigma^{\prime}$ must always be less than the unconfined compressive strength $\sigma_{\mathrm{c}}$ of the material for the behaviour to be considered brittle. In the case of materials characterized by very low values of the constant $m$, such as the Indian limestone considered in Fig. $9(m=3 \cdot 2)$, the value of $\sigma^{\prime}=\sigma_{\mathrm{c}}$ may fall beyond the brittle-ductile transition. However, for most rocks encountered in practical engineering applications, this rule of thumb appears to be adequate.

\section{SHEAR STRENGTH OF DISCONTINUITIES}

The shear strength of discontinuities in rock has been extensively discussed by a number of authors such as Patton (1966), Goodman (1970), Ladanyi \& Archambault (1970), Barton (1971, 1973, 1974), Barton \& Choubey (1977) and Richards \& Cowland (1982). These discussions have been summarized by Hoek \& Bray (1981).

For practical field applications involving the estimation of the shear strength of rough discontinuity surfaces in rock, the Author recommends the following empirical relationship between shear strength $(\tau)$ and effective normal stress $\left(\sigma^{\prime}\right)$ proposed by Barton $(1971,1973)$.

$$
\tau=\sigma^{\prime} \operatorname{Tan}\left(\phi_{b}{ }^{\prime}+\operatorname{JRC} \log _{10}\left(\mathrm{JCS} / \sigma^{\prime}\right)\right)
$$

where $\phi_{\mathrm{b}}{ }^{\prime}$ is the 'basic' friction angle of smooth planar discontinuities in the rock under consideration, JRC is a joint roughness coefficient which ranges from 5 for smooth surfaces, to 20 for rough undulating surfaces, and JCS is the joint wall compressive strength which, for clean unweathered discontinuities, equals the uniaxial compressive strength of the intact rock material.

While Barton's equation is very useful for field applications, it is not the only one which can be used for fitting to laboratory shear test data, e.g. Krsmanovic (1967), Martin \& Miller (1974) and Hencher \& Richards (1982).

Figure 10 gives a plot of direct shear strength data obtained by Martin \& Miller (1974) from tests on $150 \mathrm{~mm}$ by $150 \mathrm{~mm}$ joint surfaces in moderately weathered greywacke (grade 3, test sample number 7). Barton's empirical criterion (equation (13)) was fitted by trial and error, and the dashed curve plotted in Fig. 10 is defined by $\phi_{\mathrm{b}}{ }^{\prime}=20^{\circ}, \mathrm{JRC}=17$ and $\mathrm{JCS}=20 \mathrm{MPa}$.

Also included in Fig. 10 is a Mohr envelope defined by equations (6) and (7) for $\sigma_{\mathrm{c}}=20 \mathrm{MPa}$, $m=0-58$ and $s=0$ (determined by the method described in Appendix 1). This curve is just as good a fit to the experimental data as Barton's curve.

A number of analyses, such as that presented in Fig. 10, have convinced the Author that equations (6) and (7) provide a reasonably accurate prediction of the shear strength of rough discontinuities in rock under a wide range of effective 


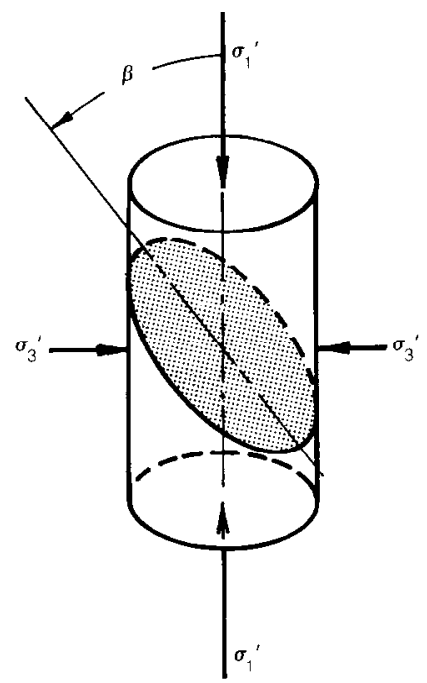

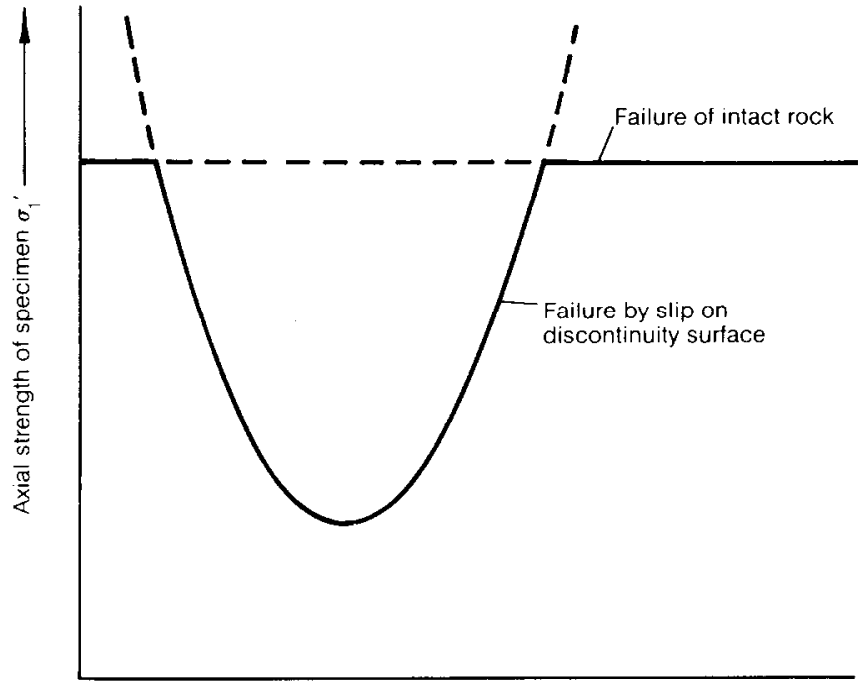

Discontinuity inclination $\beta$

(a)

(b)

Fig. 11. (a) Configuration of triaxial test specimen containing a pre-existing discontinuity; (b) strength of specimen predicted by means of equations (14) and (3)

normal stress conditions. This fact is useful in the study of schistose and jointed rock mass strength which follows.

\section{STRENGTH OF SCHISTOSE ROCK}

In the earlier part of this Paper, the discussion on the strength of intact rock was based on the assumption that the rock was isotropic, i.e. its strength was the same in all directions. A common problem encountered in rock mechanics involves the determination of the strength of schistose or layered rocks such as slates or shales.

If it is assumed that the shear strength of the discontinuity surfaces in such rocks is defined by an instantaneous friction angle $\phi_{\mathrm{i}}{ }^{\prime}$ and an instantaneous cohesion $c_{i}^{\prime}$ (see Fig. 3), then the axial strength $\sigma_{1}{ }^{\prime}$ of a triaxial specimen containing inclined discontinuities is given by the following equation (see Jaeger \& Cook, 1969, pp. 65-68)

$$
\sigma_{1}{ }^{\prime}=\sigma_{3}{ }^{\prime}+\frac{2\left(c_{\mathrm{i}}{ }^{\prime}+\sigma_{3}{ }^{\prime} \operatorname{Tan} \phi_{\mathrm{i}}{ }^{\prime}\right)}{\left(1-\operatorname{Tan} \phi_{\mathrm{i}}{ }^{\prime} \operatorname{Tan} \beta\right) \operatorname{Sin} 2 \beta}
$$

where $\sigma_{3}{ }^{\prime}$ is the minimum principal stress or confining pressure, and $\beta$ is the inclination of the discontinuity surfaces to the direction of the major principal stress $\sigma_{1}$ as shown in Fig. 11(a).

Equation (14) can only be solved for values of $\beta$ within about $25^{\circ}$ of the friction angle $\phi^{\prime}$. Very small values of $\beta$ will give very high values for $\sigma_{1}{ }^{\prime}$, while values of $\beta$ close to $90^{\circ}$ will give negative (and hence meaningless) valuès for $\sigma_{1}{ }^{\prime}$. The physical significance of these results is that slip on the discontinuity surfaces is not possible, and failure will occur through the intact material as predicted by equation (3). A typical plot of the axial strength $\sigma_{1}{ }^{\prime}$ against the angle $\beta$ is given in Fig. 11(b).

If it is assumed that the shear strength of the discontinuity surfaces can be defined by equations (6) and (7), as discussed previously, then in order to determine the values of $\phi_{i}^{\prime}$ and $c_{i}^{\prime}$ for substitution into equation (14), the effective normal stress $\sigma^{\prime}$ acting across the discontinuity must be known. This is found from

$$
\sigma^{\prime}=\frac{1}{2}\left(\sigma_{1}{ }^{\prime}+\sigma_{3}{ }^{\prime}\right)-\frac{1}{2}\left(\sigma_{1}{ }^{\prime}-\sigma_{3}{ }^{\prime}\right) \operatorname{Cos} 2 \beta
$$

However, since $\sigma_{1}{ }^{\prime}$ is the strength to be determined, the following iterative process can be used

(a) Calculate the strength $\sigma_{1 \mathrm{i}}$ ' of the intact material by means of equation (3), using the appropriate values of $\sigma_{\mathrm{c}}, m$ and $s$.

(b) Determine values of $m_{\mathbf{j}}$ and $s_{\mathbf{j}}$ for the joint (discontinuity) surfaces from direct shear or triaxial test data. The value of $\sigma_{c}$, the unconfined compressive strength, is the same for the intact material and the discontinuity surfaces in this analysis.

(c) Use the value of $\sigma_{1 \mathrm{i}}{ }^{\prime}$, calculated in (a), to obtain the first estimate of the effective normal stress $\sigma^{\prime}$ from equation (15). 


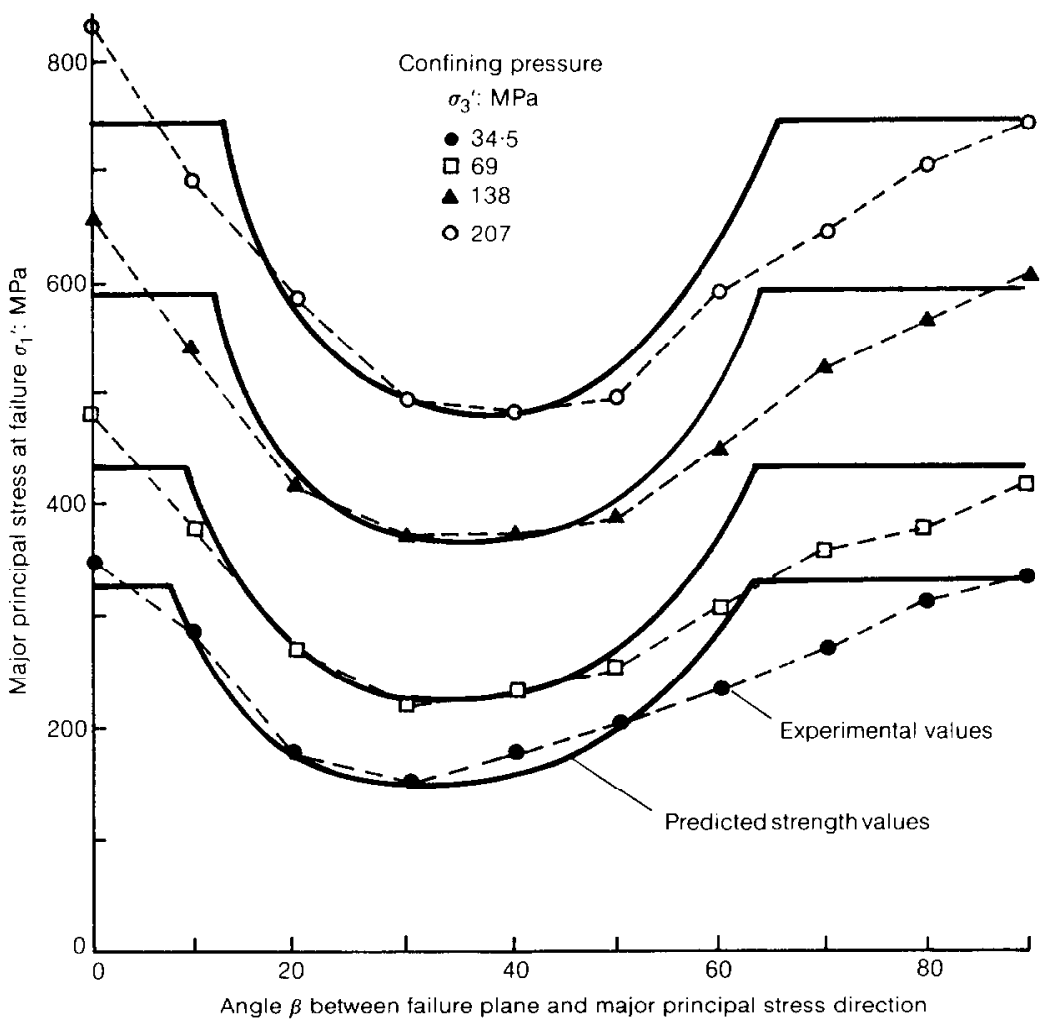

Fig. 12. Triaxial test results for slate with different failure plane inclinations, obtained by McLamore \& Gray (1967), compared with strength predictions from equations (3) and (14)

(d) Calculate $\tau, \phi_{\mathrm{i}}{ }^{\prime}$ and $c_{\mathrm{i}}{ }^{\prime}$ from equations (6)-(8), using the value of $m_{\mathrm{j}}$ and $s_{\mathrm{j}}$ from $(b)$, and the value of $\sigma^{\prime}$ from $(c)$.

(e) Calculate the axial strength $\sigma_{1 j}$ from equation (14).

( $f$ ) If $\sigma_{1 \mathrm{j}}{ }^{\prime}$ is negative or greater than $\sigma_{1 \mathrm{i}}{ }^{\prime}$, the failure of the intact material occurs in preference to. slip on the discontinuity, and the strength of the specimen is defined by equation (3).

(a) If $\sigma_{1 j}$ is less than $\sigma_{1 i}$ then failure occurs as a result of slip on the discontinuity. In this case, return to $(c)$ and use the axial strength calculated in $(e)$ to calculate a new value for the effective normal stress $\sigma^{\prime}$.

(h) Continue this iteration until the difference between successive values of $\sigma_{1 j}{ }^{\prime}$ in $(e)$ is less than $1 \%$. Only three or four iterations are required to achieve this level of accuracy.

Examples of the analysis described above are given in Figs 12 and 13.

The results of triaxial tests on slate tested by McLamore \& Gray (1967) for a range of confining pressures and cleavage orientations are plotted in Fig. 12. The solid curves have been calculated, using the method outlined above, for $\sigma_{\mathrm{c}}=217 \mathrm{MPa}$ (unconfined strength of intact rock), $m=5.25$ and $s=1.00$ (constants for intact rock), and $m_{\mathbf{j}}=1.66$ and $s_{\mathbf{j}}=0.006$ (constants for discontinuity surfaces).

The values of the constants $m_{\mathrm{j}}$ and $s_{\mathrm{j}}$ for the discontinuity surfaces were determined by statistical analysis of the minimum axial strength values, using the procedure for broken rock described in Appendix 1.

A similar analysis is presented in Fig. 13, which gives results from triaxial tests on sandstone by Horino \& Ellikson (1970). In this case the discontinuity surfaces were created by intentionally fracturing intact sandstone in order to obtain very rough fresh surfaces. The constants used in plotting the solid curves in Fig. 13 were $\sigma_{\mathrm{c}}=177.7 \mathrm{MPa}$ (intact rock strength), $m=22.87$ and $s=1.00$ (constants for intact rock), and $m_{\mathrm{j}}=4.07$ and $s_{\mathrm{j}}=0$ (constants for induced fracture planes).

The rougher failure surfaces in the sandstone, as compared to the slate (compare values of $m_{\mathrm{j}}$ ), give more sudden changes in axial strength with discontinuity inclination. In both these cases, and in a number of other examples analysed, the agreement between measured and predicted 


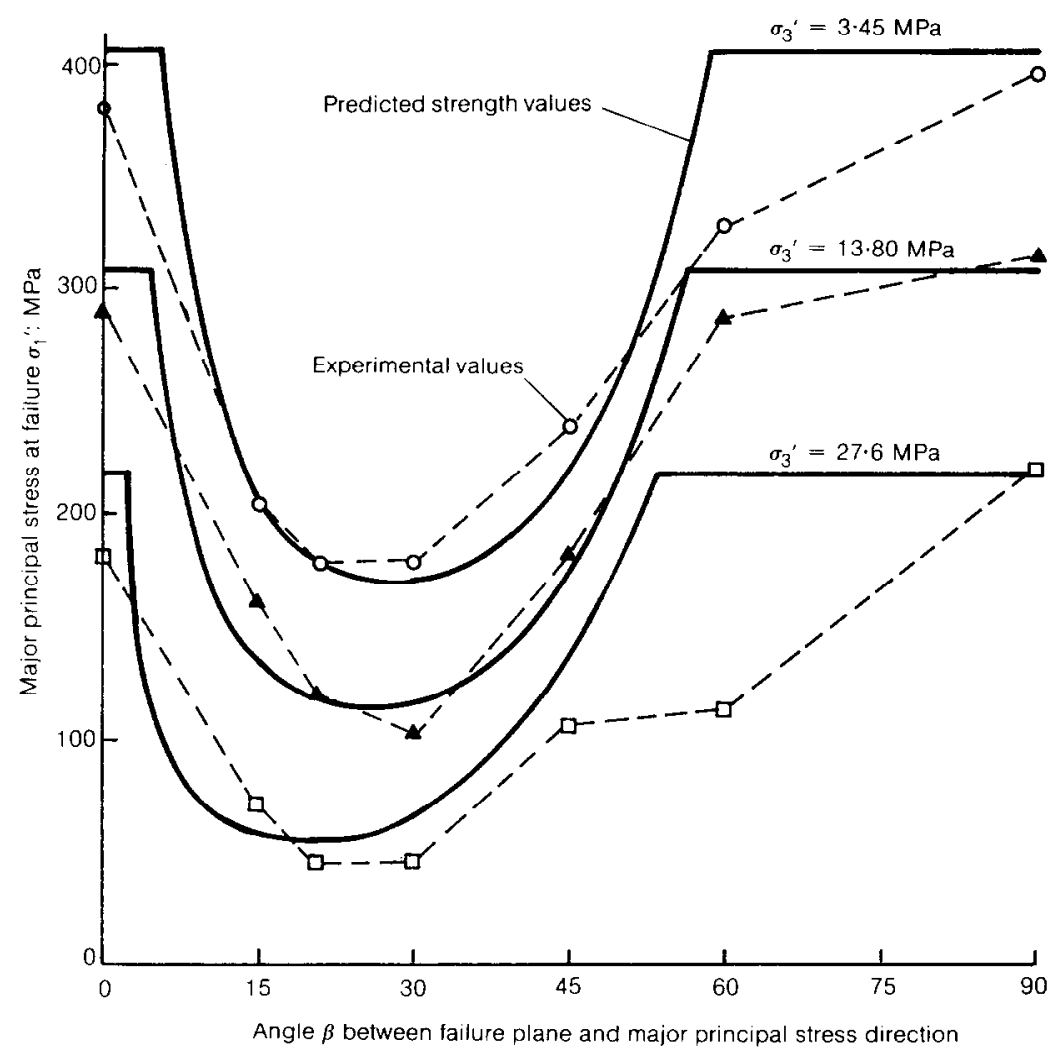

Fig. 13. Triaxial test results for fractured sandstone, tested by Horino \& Ellikson (1970), compared with predicted anisotropic strength

strengths is adequate for most practical design purposes.

An example of the application of the analysis of anisotropic failure, is given later. This example involves the determination of the stress distribution and potential failure zones in highly stressed schistose rock surrounding a tunnel.

\section{FAILURE OF JOINTED ROCK MASSES}

Having studied the strength of intact rock and of discontinuities in rock, the next logical step is to attempt to predict the behaviour of a jointed rock mass containing several sets of discontinuities. The simplest approach to this problem is to superimpose a number of analyses for individual discontinuity sets, such as those presented in Figs 12 and 13, in the hope that the overall behaviour pattern obtained would be representative of the behaviour of an actual jointed rock mass.

Verification of the results of such predictions presents very complex experimental problems, and many research workers have resorted to the use of physical models in an attempt to minimize these experimental difficulties. Lama \& Vutukuri (1978) have summarized the results of model studies carried out by John (1962), Muller \& Pacher (1965), Lajtai (1967), Einstein, Nelson, Bruhn \& Hirschfield (1969), Ladanyi \& Archambault (1970, 1972), Brown (1970), Brown \& Trollope (1970), Walker (1971) and others. One of these studies, published by Ladanyi \& Archambault (1972), will be considered here.

Ladanyi \& Archambault constructed models from rods, with a square cross-section of $12.7 \mathrm{~mm}$ by $12.7 \mathrm{~mm}$ and a length of $63.5 \mathrm{~mm}$, which had been sawn from commercial compressed concrete bricks. The Mohr failure envelopes for the intact concrete material and for the sawn 'joints' in the model are given in Fig. 14. These curves were derived by statistical analysis of raw test data supplied by Professor Ladanyi.

One of the model configurations used by Ladanyi \& Archambault (1972) is illustrated in Fig. 15. Failure of the model in the direction of the "cross joints' (inclined at an angle $\alpha$ to the major principal stress direction) involves fracture of intact material as well as sliding on the joints. A crude first approximation of the model strength in the $\alpha$ direction is obtained by simple averaging of the Mohr failure envelopes for the intact material 


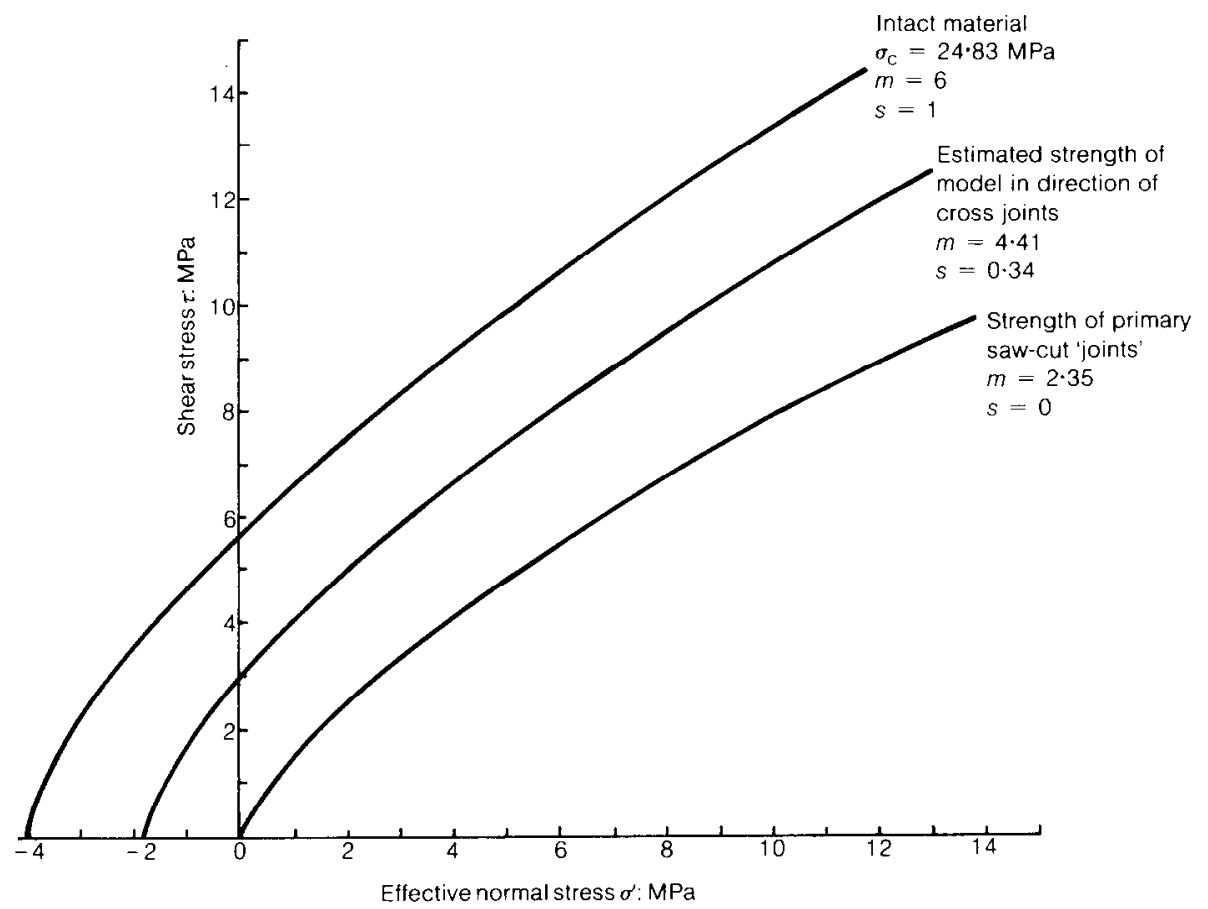

Fig. 14. Mohr failure envelopes for brickwall model tested by Ladanyi \& Archambault (1972)

and $\dot{*}$ the through-going joints. The resulting strength estimate is plotted as a Mohr envelope in Fig. 14.

The predicted strength behaviour of Ladanyi \& Archambaults' 'brickwall' model, for different joint orientations and lateral stress levels, is given in Fig. 16(a). These curves have been calculated, from the strength values given in Fig. 14, by means of equations (14), (15) and (3). The actual strength values measured by Ladanyi \& Archambault are plotted in Fig. 16(b). Comparison between these two figures leads to the following conclusions

(a) There is an overall similarity between predicted and observed strength behaviour which suggests that the approach adopted in deriving the curves plotted in Fig. 16(a) is not entirely inappropriate.

(b) The observed strengths are generally lower than the predicted strengths. The intact matcrial strength is not achieved, even at the most favourable joint orientations. The sharply defined transitions between different failure modes, predicted in Fig. 16(a), are smoothed out by rotation and crushing of individual blocks. This behaviour is illustrated in the series of photographs reproduced in Fig. 17. In particular, the formation of 'kink bands', as illustrated in Fig. 17(c), imparts a great deal of mobility to the model and results in a

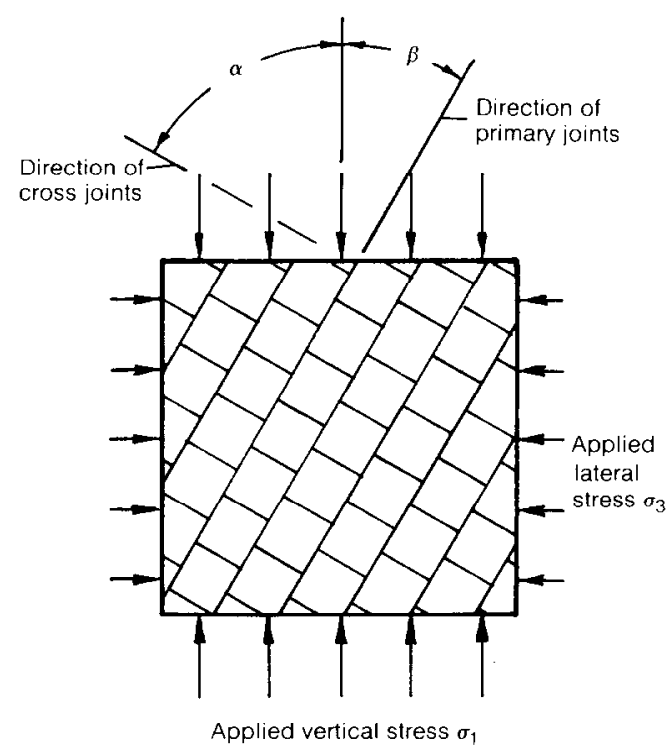

Fig. 15. Configuration of brickwall model tested by Ladanyi \& Archambault (1972) 

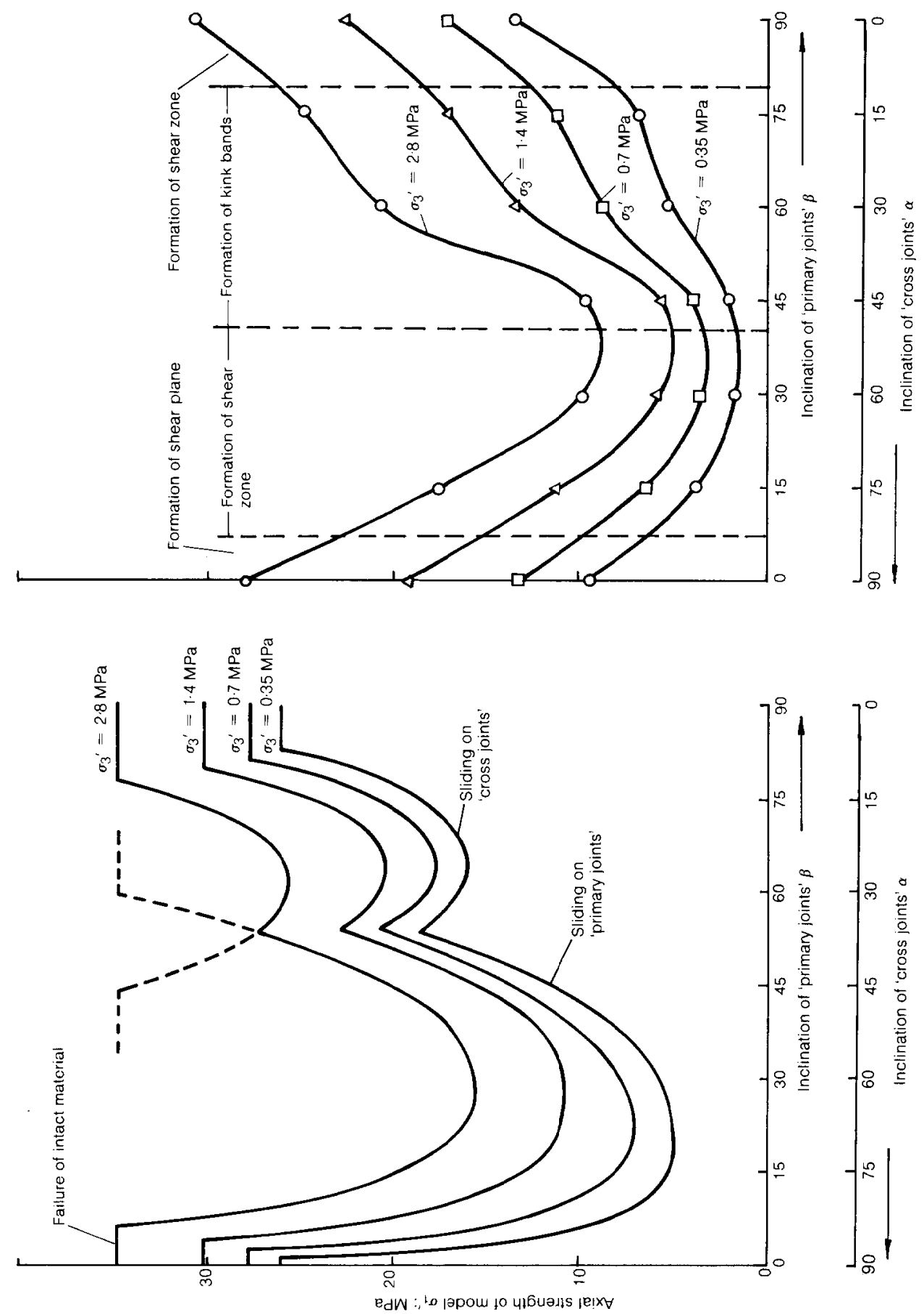

竞 


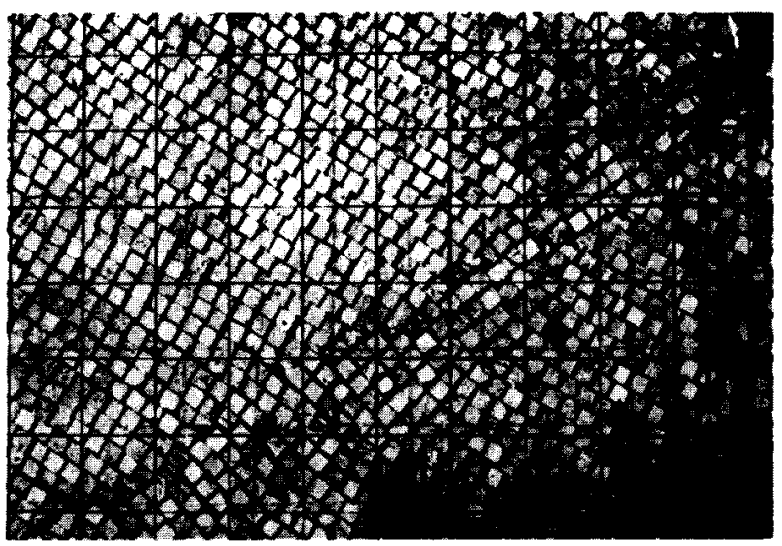

을
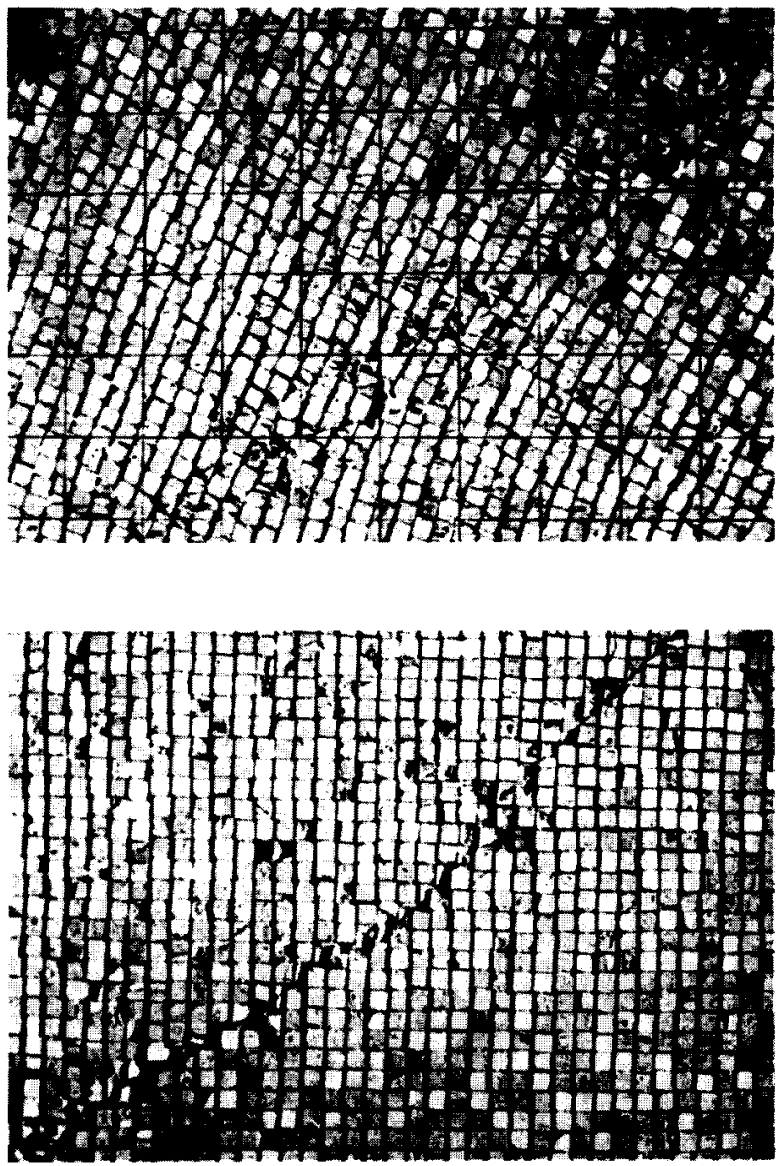

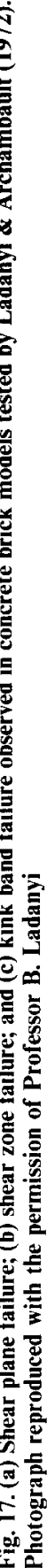




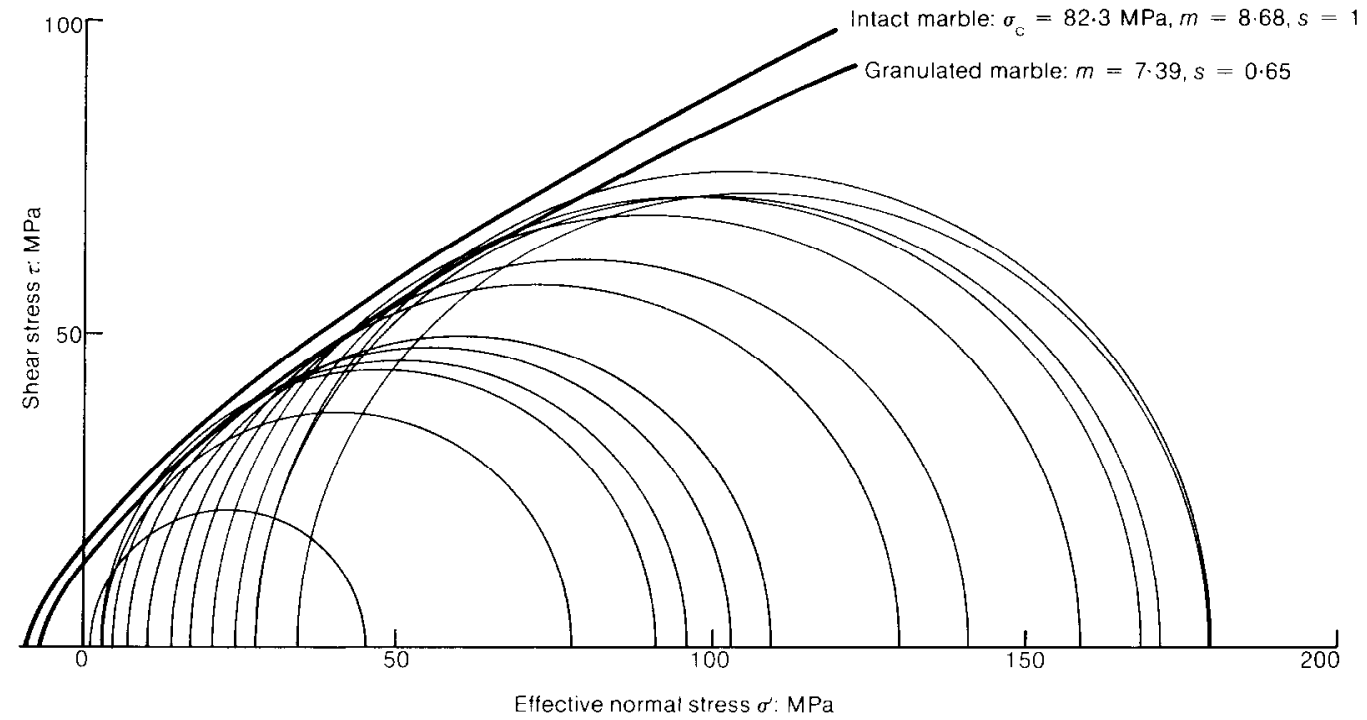

Fig. 18. Comparison between the strengths of intact and granulated Carrara marble tested by Gerogiannopoulos (1979)

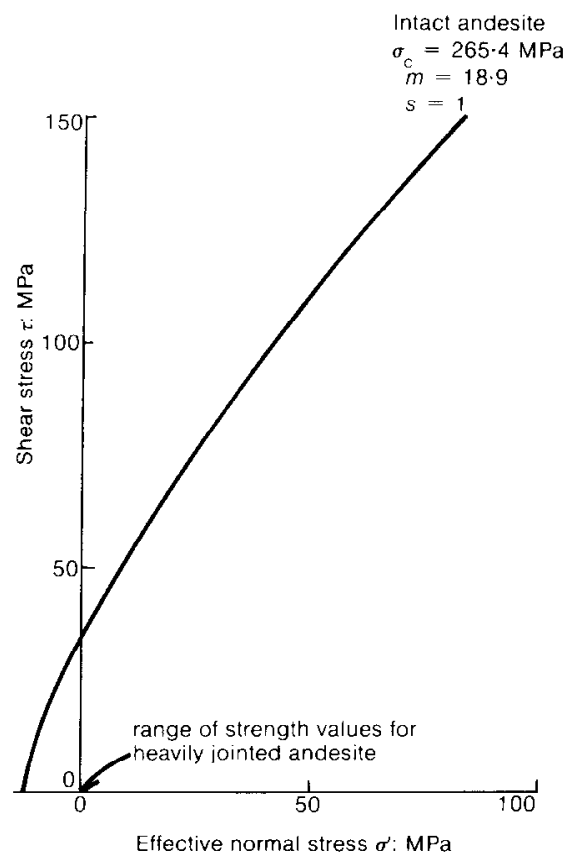

(a)

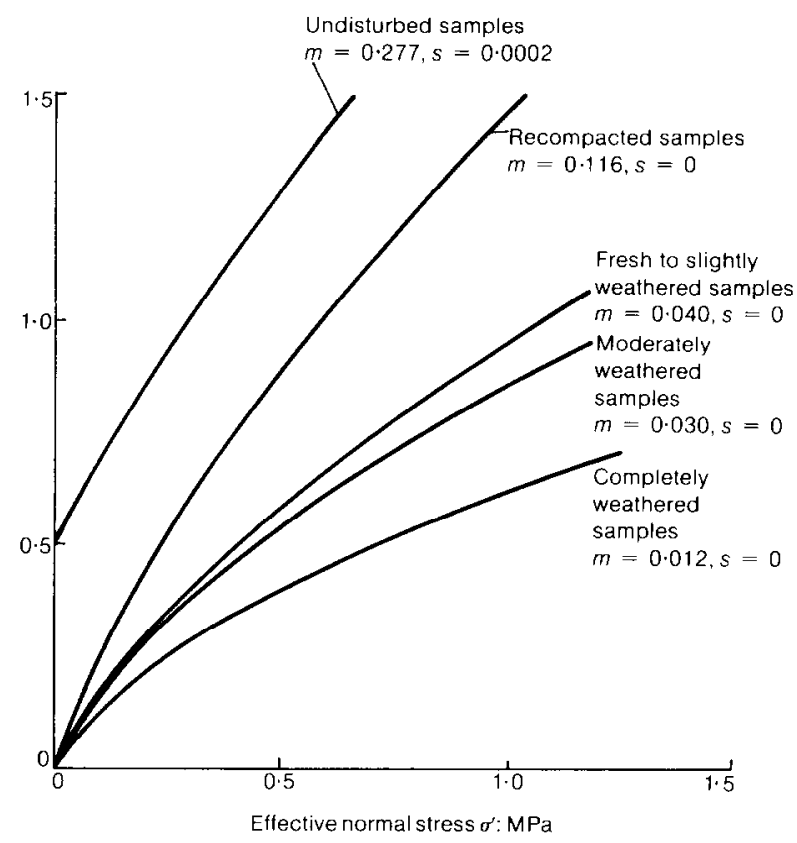

(b)

Fig. 19. Mohr failure envelopes for (a) intact and (b) heavily jointed Panguna andesite from Bougainville, Papua New Guinea (see Table 3 for description of materials) 
Table 3. Details of materials and test procedures for Panguna andesite

\begin{tabular}{|c|c|c|c|}
\hline Material & Tested by & $\begin{array}{c}\text { Sample } \\
\text { diameter: } \mathrm{mm}\end{array}$ & Material constants \\
\hline Intact Panguna andesite & $\begin{array}{l}\text { Jaeger }(1970) \\
\text { Golder Associates }\end{array}$ & $\begin{array}{l}25 \\
50\end{array}$ & $\begin{array}{l}\qquad \begin{array}{l}\sigma_{\mathrm{c}}=265 \cdot 4 \mathrm{MPa} \\
m=18 \cdot 9 \\
\quad s=1\end{array} \\
\text { Correlation } \\
\text { coefficient } 0.85\end{array}$ \\
\hline $\begin{array}{l}\text { Undisturbed core samples of heavily } \\
\text { jointed andesite obtained by triple- } \\
\text { tube diamond core drilling in } \\
\text { exploration adit }\end{array}$ & Jaeger (1970) & 152 & 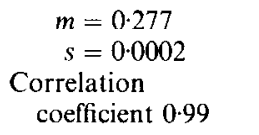 \\
\hline $\begin{array}{l}\text { Recompacted sample of heavily jointed } \\
\text { andesite collected from mine benches } \\
\text { (equivalent to compacted fresh rock- } \\
\text { fill) }\end{array}$ & Bougainville Copper & 152 & $\begin{aligned} m & =0 \cdot 116 \\
s & =0\end{aligned}$ \\
\hline $\begin{array}{l}\text { Fresh to slightly weathered andesite, } \\
\text { lightly recompacted }\end{array}$ & $\begin{array}{l}\text { Snowy Mountains } \\
\text { Engineering Corporation }\end{array}$ & 570 & $\begin{aligned} m & =0 \cdot 040 \\
s & =0\end{aligned}$ \\
\hline $\begin{array}{l}\text { Moderately weathered andesite, } \\
\text { lightly recompacted }\end{array}$ & $\begin{array}{l}\text { Snowy Mountains } \\
\text { Engineering Corporation }\end{array}$ & 570 & $\begin{aligned} m & =0 \cdot 030 \\
s & =0\end{aligned}$ \\
\hline $\begin{array}{l}\text { Completely weathered andesite } \\
\text { (equivalent to poor quality waste } \\
\text { rock) }\end{array}$ & $\begin{array}{l}\text { Snowy Mountains } \\
\text { Engineering Corporation }\end{array}$ & 570 & $\begin{aligned} m & =0 \cdot 012 \\
s & =0\end{aligned}$ \\
\hline
\end{tabular}

significant strength reduction in the zone defined by $15>\alpha>45$, as shown in Fig. 16(b).

(c) Intuitive reasoning suggests that the degree of interlocking of the model blocks is of major significance in the behaviour of the model since this will control the freedom of the blocks to rotate. In other words, the freedom of a rock mass to dilate will depend on the interlocking of individual pieces of rock which, in turn, will depend on the particle shape and degree of disturbance to which the mass has been subjected. This reasoning is supported by experience in strength determination of rock fill where particle strength and shape, particle size distribution and degree of compaction are all important factors in the overall strength behaviour.

(d) Extension of the principle of strength prediction used in deriving the curves presented in Fig. 16(a) to rock masses, containing three, four or five sets of discontinuities, suggests that the behaviour of such rock masses would approximate to that of a homogeneous isotropic system. In practical terms, this means that, for most rock masses containing a number of joint sets with similar strength characteristics, the overall strength behaviour will be similar to that of a very tightly interlocking rockfill.

The importance of the degree of interlocking between particles in a homogeneous rock mass can be illustrated by considering the results of an ingenious experiment carried out by Rosengren \& Jaeger (1968), and repeated by Gerogiannopoulos (1979). By heating specimens of coarse grained marble to about $600^{\circ} \mathrm{C}$, the cementing material between grains is fractured by differential thermal expansion of the grains themselves. The material produced by this process is a very low porosity assemblage of extremely tightly interlocking but independent grains. This 'granulated' marble was tested by Rosengren \& Jaeger (1968) and Gerogiannopoulos (1979) in an attempt to simulate the behaviour of an undisturbed jointed rock mass.

The results obtained by Gerogiannopoulos from triaxial tests on both intact and granulated Carrara marble are plotted in Fig. 18. In order to avoid confusion, Mohr failure circles for the granulated material only are included in this figure. However, statistical analyses of the data sets for both intact and granulated materials to obtain $\sigma_{c}, m$ and $s$ values gave correlation coefficients in excess of $90 \%$.

Figure 18 shows that the strength difference between intact material and a very tightly interlocking assemblage of particles of the same material is relatively small. It is unlikely that this degree of interlocking would exist in an in situ rock mass, except in very massive rock at considerable depth below surface. Consequently, the Mohr failure envelope for granulated marble, presented in Fig. 18, represents the absolute upper bound for jointed rock mass strength.

A more realistic assessment of the strength of heavily jointed rock masses can be made on the 
basis of triaxial test data obtained in connection with the design of the slopes for the Bougainville open pit copper mine in Papua New Guinea. The results of some of these tests, carried out by Jaeger (1970), the Snowy Mountain Engineering Corporation and in the mine laboratories, have been summarized by Hoek \& Brown (1980a).

The results of tests on Panguna andesite are plotted as Mohr envelopes in Fig. 19. Fig. 19(a) has been included to show the large strength difference between the intact material and the jointed rock mass. Fig. 19(b) is an enlargement of the low stress portion of Fig. 19(a), and gives details of the test results on the jointed material. Details of the materials tested are given in Table 3 .

Particular mention must be made of the undisturbed $152 \mathrm{~mm}$ diameter core samples of jointed Panguna andesite tested by Jaeger (1970). These samples were obtained by careful triple-tube diamond core drilling in an exploration adit in the mine. They were shipped to Canberra, Australia, in the inner tubes of the core barrels, and then carefully transferred onto thin copper sheets which were soldered to form containers for the specimens. These specimens were then rubber sheathed and tested triaxially. This series of tests is, as far as the Author is aware, the most reliable set of tests ever carried out on 'undisturbed' jointed rock.

The entire Bougainville testing programme extended over a ten year period and cost several hundred thousand pounds. This level of effort was

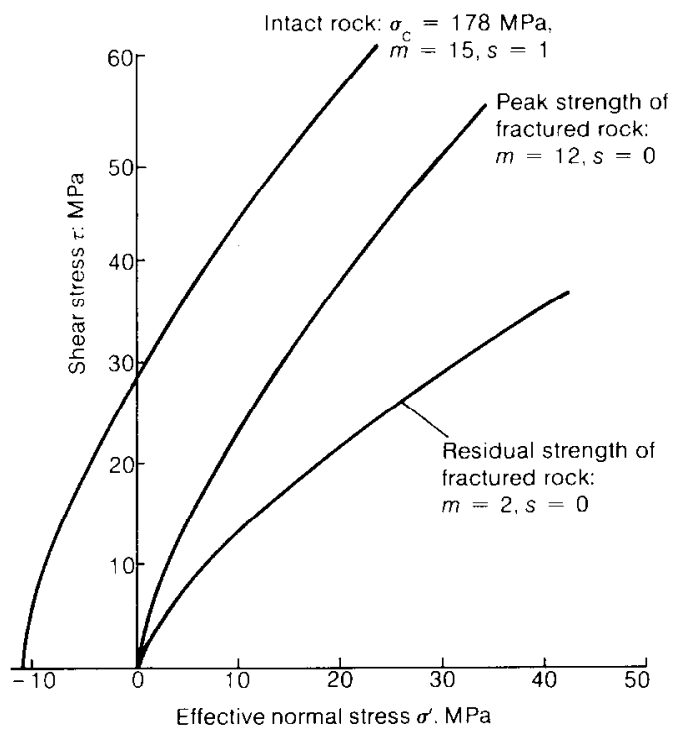

Fig. 20. Mohr failure envelopes estimated from plotted triaxial test data (Raphael \& Goodman, 1979) for highly fractured, fresh to slightly altered greywacke sandstone justified because of the very large economic and safety considerations involved in designing a final slope of almost $1000 \mathrm{~m}$ high for one side of the open pit. Unfortunately, it is seldom possible to justify testing programmes of this magnitude in either mining or civil engineering projects, and hence the results summarized in Fig. 19 represent a very large proportion of the sum total of all published data on this subject.

A similar, although less ambitious, series of tests was carried out on a highly fractured greywacke sandstone by Raphael \& Goodman (1979). The results of these tests, plotted in Fig. 20, show a much lower reduction from intacl to jointed rock mass strength than for the Panguna andesite (Fig. 19). This is presumably because the intact sandstone tested by Raphael \& Goodman is significantly weaker than the andesite tested by Jaeger, and hence there is less possibility of the block rotation mechanism (see Fig. 17(c)) which appears to contribute so much to the weakness of jointed systems in strong materials. This suggestion is highly speculative, and is based on intuitive reasoning rather than experimental facts.

\section{ESTIMATING THE STRENGTH OF JOINTED ROCK MASSES}

Based on their analyses of the results from tests on models, jointed rock masses and rockfill, Hoek \& Brown (1980b) proposed an approximate method for estimating the strength of jointed rock masses. This method, summarized in Table 4, involves estimating the values of the empirical constants $m$ and $s$ from a description of the rock mass. These estimates, together with an estimate of the uniaxial compressive strength of the intact pieces of rock, can then be used to construct an approximate Mohr failure envelope for the jointed rock mass.

As a means of assisting the user in describing the rock mass, use is made of the rock mass classification systems proposed by Bieniawski (1974b) and Barton, Lien \& Lunde (1974), which has been summarized by Hoek \& Brown (1980a).

The Author's experience in using the values listed in Table 4 for practical engineering design suggests that they are somewhat conservative. In other words, the actual rock mass strength is higher than that estimated from the Mohr envelopes plotted from the values listed. It is very difficult to estimate the extent to which the predicted strengths are too low, since reliable field data are almost non-existent. However, based on comparisons between observed and predicted behaviour of rock slopes and underground excavations, the Author tends to regard the strength estimates made from Table 4 as lower bound values for design purposes. Obviously, in 
Table 4. Approximate relationship between rock mass quality and material constants

\begin{tabular}{|c|c|c|c|c|c|c|}
\hline $\begin{aligned} & \text { Empirical failure criterion } \\
& \sigma_{1}^{\prime}=\sigma_{3}{ }^{\prime}+\left(m \sigma_{\mathrm{c}} \sigma_{3}{ }^{\prime}+s \sigma_{\mathrm{c}}{ }^{2}\right)^{1 / 2} \\
& \sigma_{1}^{\prime}= \text { major principal stress } \\
& \sigma_{3}^{\prime}= \text { minor principal stress } \\
& \sigma_{\mathrm{c}}= \text { uniaxial compressive } \\
& \text { strength of intact rock } \\
& m, s= \text { empirical constants }\end{aligned}$ & & 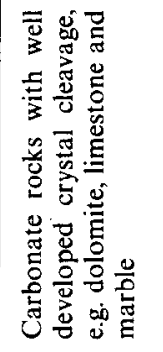 & 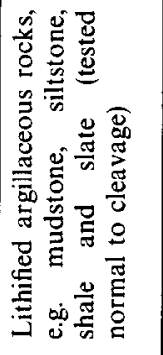 & 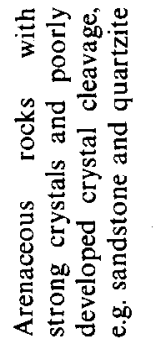 & 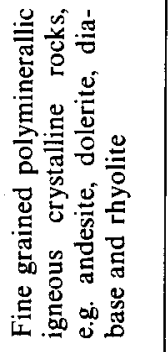 & 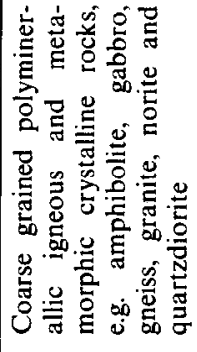 \\
\hline $\begin{array}{l}\text { Intact rock samples } \\
\text { Laboratory size samples free } \\
\quad \text { from pre-existing fractures } \\
\text { Bieniawski, 1974b (CSIR)* rating } \\
\text { Barton et al., } 1974 \text { (NGI)† rating }\end{array}$ & $\begin{array}{l}100 \\
500\end{array}$ & $\begin{array}{r}m=7 \\
s=1\end{array}$ & $\begin{aligned} m & =10 \\
s & =1\end{aligned}$ & $\begin{aligned} m & =15 \\
s & =1\end{aligned}$ & $\begin{aligned} m & =17 \\
s & =1\end{aligned}$ & $\begin{array}{c}m=25 \\
s=1\end{array}$ \\
\hline $\begin{array}{l}\text { Very good quality rock mass } \\
\text { Tightly interlocking undisturbed } \\
\text { rock with rough unweathered } \\
\text { joints spaced at } 1 \text { to } 3 \mathrm{~m} \\
\text { Bieniawski, } 1974 \mathrm{~b} \text { (CSIR) rating } \\
\text { Barton et al., } 1974 \text { (NGI) rating }\end{array}$ & $\begin{array}{r}85 \\
100\end{array}$ & $\begin{aligned} m & =3.5 \\
s & =0 \cdot 1\end{aligned}$ & $\begin{aligned} m & =5 \\
s & =0.1\end{aligned}$ & $\begin{aligned} m & =7 \cdot 5 \\
s & =0 \cdot 1\end{aligned}$ & $\begin{aligned} m & =8.5 \\
s & =0 \cdot 1\end{aligned}$ & $\begin{aligned} m & =12 \cdot 5 \\
s & =0 \cdot 1\end{aligned}$ \\
\hline $\begin{array}{l}\text { Good quality rock mass } \\
\text { Fresh to slightly weathered } \\
\text { rock, slightly disturbed with } \\
\text { joints spaced at } 1 \text { to } 3 \mathrm{~m} \\
\text { Bieniawski, 1974b (CSIR) rating } \\
\text { Barton et al., } 1974 \text { (NGI) rating }\end{array}$ & $\begin{array}{l}65 \\
10\end{array}$ & $\begin{aligned} m & =0.7 \\
s & =0.004\end{aligned}$ & $\begin{aligned} m & =1 \\
s & =0.004\end{aligned}$ & $\begin{aligned} m & =1 \cdot 5 \\
s & =0.004\end{aligned}$ & $\begin{aligned} m & =1.7 \\
s & =0.004\end{aligned}$ & $\begin{aligned} m & =2.5 \\
s & =0.004\end{aligned}$ \\
\hline $\begin{array}{l}\text { Fair quality rock mass } \\
\text { Several sets of moderately } \\
\text { weathered joints spaced at } \\
0.3 \text { to } 1 \mathrm{~m} \text {, disturbed } \\
\text { Bieniawski, 1974b (CSIR) rating } \\
\text { Barton et al., } 1974 \text { (NGI) rating }\end{array}$ & $\begin{array}{r}44 \\
1\end{array}$ & $\begin{aligned} m & =0.14 \\
s & =0.0001\end{aligned}$ & $\begin{aligned} m & =0.20 \\
s & =0.0001\end{aligned}$ & $\begin{aligned} m & =0.30 \\
s & =0.0001\end{aligned}$ & $\begin{aligned} m & =0.34 \\
s & =0.0001\end{aligned}$ & $\begin{aligned} m & =0.50 \\
s & =0.0001\end{aligned}$ \\
\hline $\begin{array}{l}\text { Poor quality rock mass } \\
\text { Numerous weathered joints at } \\
30 \text { to } 500 \mathrm{~mm} \text { with some gouge. } \\
\text { Clean, compacted rockfill } \\
\text { Bieniawski, 1974b (CSIR) rating } \\
\text { Barton et al., 1974 (NGI) rating }\end{array}$ & $\begin{array}{r}23 \\
0 \cdot 1\end{array}$ & $\begin{aligned} m & =0.04 \\
s & =0.00001\end{aligned}$ & $\begin{aligned} m & =0.05 \\
s & =0.00001\end{aligned}$ & $\begin{aligned} m & =0.08 \\
s & =0.00001\end{aligned}$ & $\begin{aligned} m & =0.09 \\
s & =0.00001\end{aligned}$ & $\begin{aligned} m & =0.13 \\
s & =0.00001\end{aligned}$ \\
\hline $\begin{array}{l}\text { Very poor quality rock mass } \\
\text { Numerous heavily weathered } \\
\text { joints spaced at } 50 \mathrm{~mm} \text { with } \\
\text { gouge. Waste rock } \\
\text { Bieniawski, 1974b (CSIR) rating } \\
\text { Barton et al., } 1974 \text { (NGI) rating }\end{array}$ & $\begin{array}{r}3 \\
0-01\end{array}$ & $\begin{aligned} m & =0.007 \\
s & =0\end{aligned}$ & $\begin{aligned} m & =0 \cdot 010 \\
s & =0\end{aligned}$ & $\begin{aligned} m & =0.015 \\
s & =0\end{aligned}$ & $\begin{aligned} m & =0.017 \\
s & =0\end{aligned}$ & $\begin{aligned} m & =0.025 \\
s & =0\end{aligned}$ \\
\hline
\end{tabular}

* CSIR Commonwealth Scientific and Industrial Research Organization.

$\dagger$ NGI Norway Geotechnical Institute. 


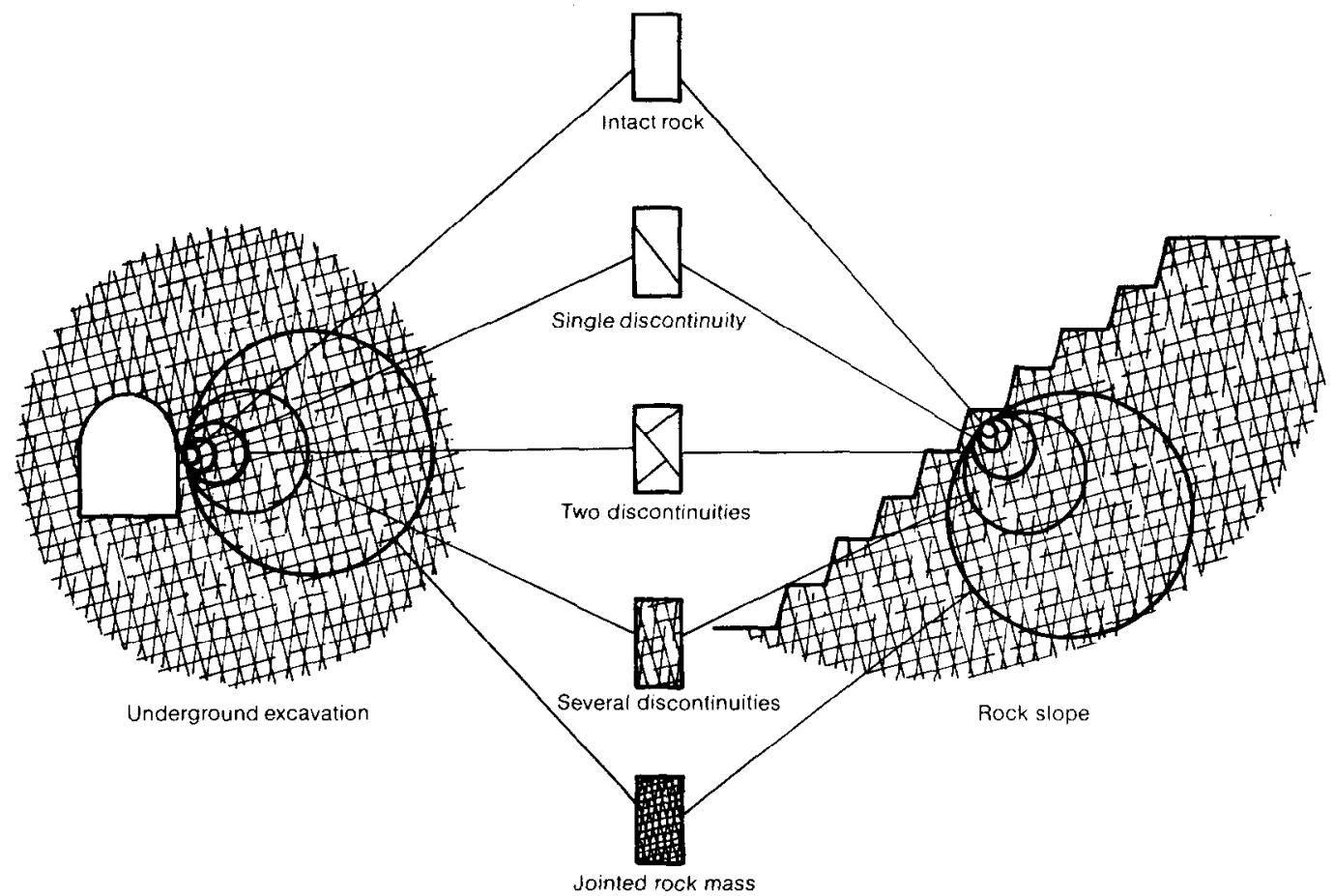

Fig. 21. Simplified representation of the influence of scale on the type of rock mass behaviour model which should be used in designing underground excavations or rock slopes

designing an important structure, the user would be well advised to attempt to obtain his own test data before deciding to use strength values significantly higher than those given by Table 4 .

In order to use Table 4 to make estimates of rock mass strength, the following steps are suggested:

(a) From a geological description of the rock mass, and from a comparison between the size of the structure being designed and the spacing of discontinuities in the rock mass (see Fig. 21), decide which type of material behaviour model is most appropriate. The values listed in Table 4 should only be used for estimating the strength of intact rock or of heavily jointed rock masses containing several sets of discontinuitics of similar type. For schistose rock or for jointed rock masses containing dominant discontinuities such as faults, the behaviour will be anisotropic and the strength should be dealt with in the manner described in Example 1.

(b) Estimate the unconfined compressive strength $\sigma_{c}$ of the intact rock pieces from laboratory test data, index values or descriptions of rock hardness (see Hoek \& Bray, 1981 or Hoek \& Brown, 1980a). This strength estimate is important since it establishes the scale of the Mohr failure envelope.

(c) From a description of the rock mass or, preferably, from a rock mass classification using the system of Barton et al. (1974) or Bieniawski (1974b), determine the appropriate row and column in Table 4.

(d) Using equations (6) and (7), calculate and plot a Mohr failure envelope for the estimated values of $\sigma_{\mathrm{c}}, m$ and $s$. Draw an approximate average Mohr-Coulomb linear envelope through the plotted points, and estimate the average friction angle and cohesive strength of the rock mass. Compare these values with published data for rockfill (Marachi, et al., 1972; Marsal, 1967, 1973; Charles \& Watts, 1980) or with data given in this Paper to ensure that the values are reasonable.

(e) Use the estimated strength values for preliminary design purposes and carry out sensitivity studies by varying the values of $m$ and $s$ to determine the importance of rock mass strength in the design.

$(f)$ For critical designs which are found to be very sensitive to variations in rock mass strength, establish a site investigation and laboratory testing programme aimed at refining the 


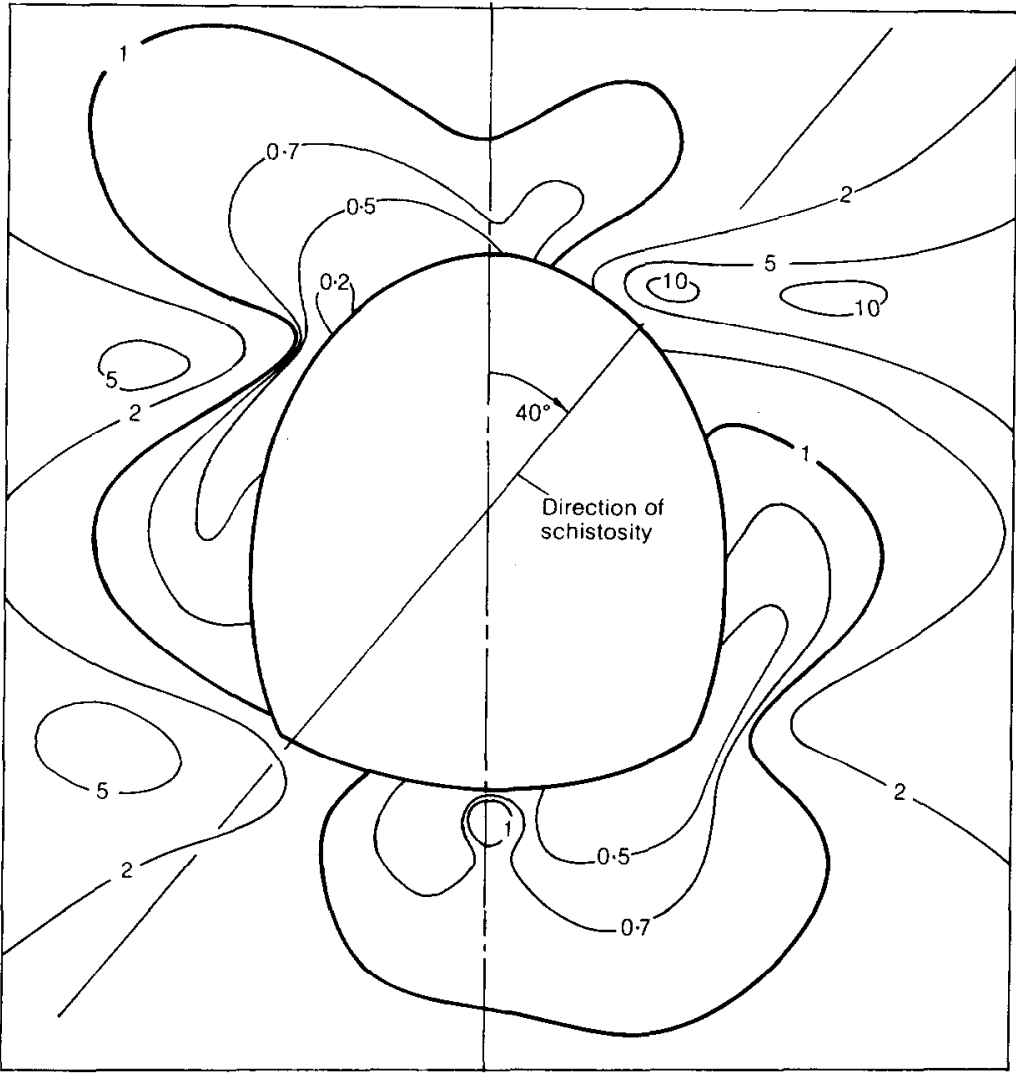

Fig. 22. Contours of ratio of available strength to stress in schistose rock surrounding a highly stressed tunnel

strength estimates made on the basis of the procedure outlined in the preceding steps.

\section{EXAMPLES OF APPLICATION OF ROCK MASS STRENGTH ESTIMATES IN ENGINEERING DESIGN}

In order to illustrate the application of the empirical failure criterion presented to practical engineering design problems, three examples are given. These examples have been carefully chosen to illustrate particular points and, although all of the examples are hypothetical, they are based on actual engineering problems studied by the Author.

\section{Example 1}

Figure 22 gives a set of contours of the ratio of available strength to induced stress in a schistose gneiss rock mass surrounding a tunnel. The following assumptions were made in calculating these ratios.

The vertical in situ stress in the rock surrounding the tunnel is $40 \mathrm{MPa}$, corresponding to a depth below surface of about $1500 \mathrm{~m}$. The horizontal in situ stress is $60 \mathrm{MPa}$ or 1.5 times the vertical stress.

The rock strength is defined by the following constants: uniaxial compressive strength of intact rock $\left(\sigma_{\mathrm{c}}=150 \mathrm{MPa}\right)$, material constants for the isotropic rock mass $\left(m_{\mathrm{i}}=12.5, s_{\mathrm{i}}=0.1\right)$ material constants for joint strength in direction of schistosity $\left(m_{\mathrm{j}}=0.28, s_{\mathrm{j}}=0.0001\right)$.

The direction of schistosity is assumed to be at $40^{\circ}$ (measured in a clockwise direction) to the vertical axis of the tunnel.

The rock mass surrounding the tunnel is assumed to be elastic and isotropic. This assumption is generally accurate enough for most practical purposes, provided that the ratio of elastic moduli parallel to and normal to the schistosity does not exceed three. In the case of the example illustrated in Fig. 22, the stress distribution was calculated by means of the twodimensional boundary element stress analysis technique, using the programme listing published by Hoek \& Brown (1980a). A modulus of elasticity 


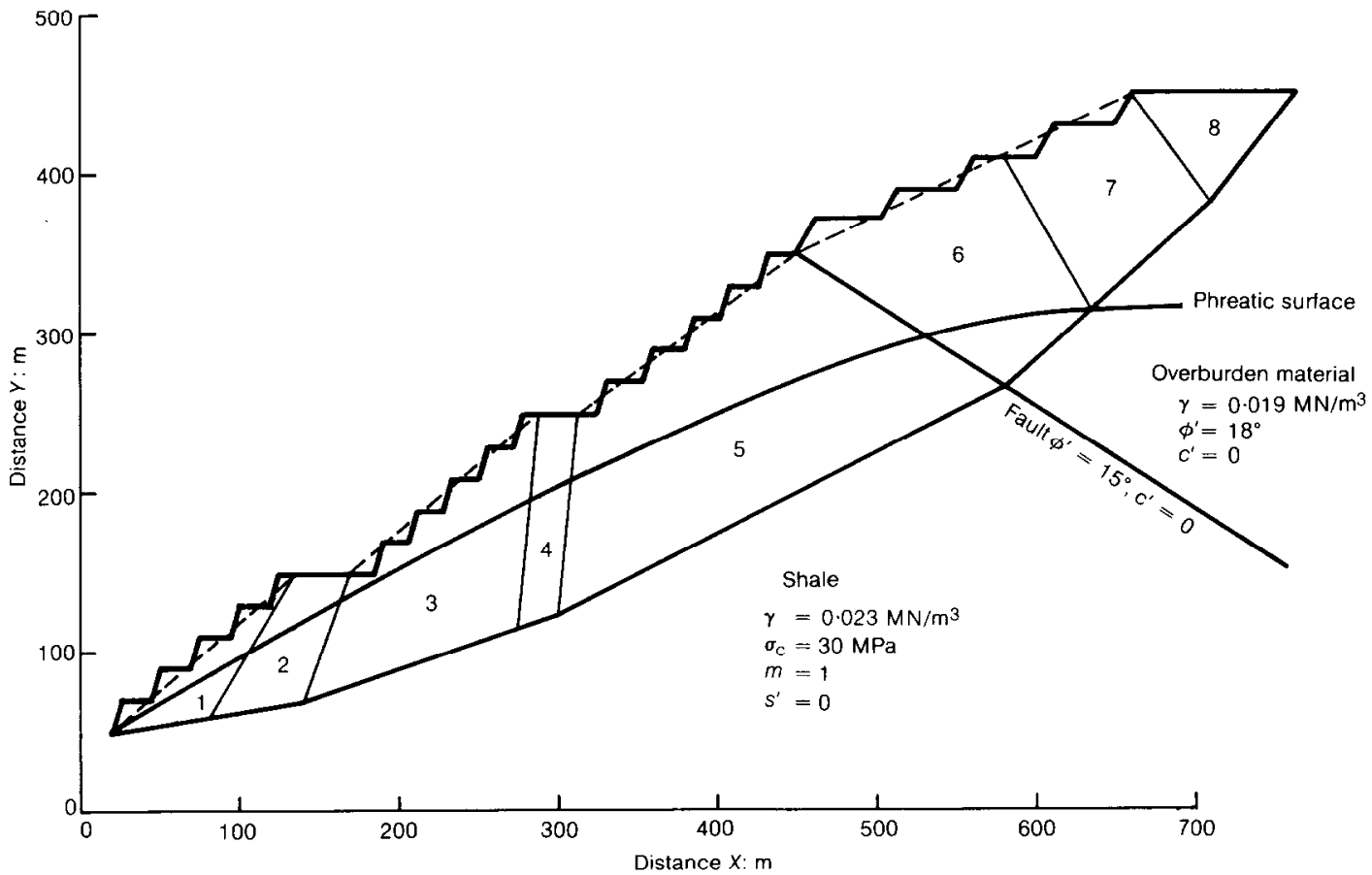

Fig. 23. Rock slope analysed in example 2 (see Table 5 for co-ordinates of slope profile, phreatic surface and failure surface)

of $E=70 \mathrm{GPa}$ and a Poisson's ratio $v=0.25$ were assumed for this analysis.

The shear and normal stresses $\tau$ and $\sigma^{\prime}$, acting on a plane inclined at $40^{\circ}$ (clockwise) to the vertical axis, were calculated for each point on a grid surrounding the tunnel. The available shear strengths in the direction of this plane, $\tau_{\text {as }}$, were calculated by means of equations (7) and (6) (for $\sigma_{\mathrm{c}}=150 \mathrm{MPa}, m_{\mathrm{j}}=0.28$ and $\left.s_{\mathrm{j}}=0.0001\right)$. Hence, the ratio of availablc shcar strength $\tau_{\text {as }}$ to the induced shear stress $\tau$ was determined for each grid point.

In addition, the available strength $\sigma_{\mathrm{a} i}{ }^{\prime}$ of the isotropic rock mass was calculated at each grid point by means of equation (3), using the principal stresses $\sigma_{1}{ }^{\prime}$ and $\sigma_{3}{ }^{\prime}$ and the isotropic rock mass material properties $\left(\sigma_{\mathrm{c}}=150 \mathrm{MPa}, m_{\mathrm{i}}=12.5\right.$ and $s_{\mathrm{i}}=0 \cdot 1$ ). This available strength $\sigma_{\mathrm{ai}}{ }^{\prime}$ was compared with the induced maximum principal stress $\sigma_{1}{ }^{\prime}$ to obtain the ratio $\sigma_{\mathrm{ai}}{ }^{\prime} / \sigma_{1}{ }^{\prime}$ at each grid point.

In plotting the contours illustrated in Fig. 22, the lower of the two ratios $\tau_{\mathrm{as}} / \tau$ and $\sigma_{\mathrm{ai}}{ }^{\prime} / \sigma_{1}{ }^{\prime}$ was used to define the strength to stress ratio value.

The zones surrounded by the contours defined by a strength to stress ratio of one contain overstressed rock. The general method used in designing tunnels and caverns in highly stressed rock is to attempt to minimize the extent of such overstressed zones hy choice of the excavation shape and orientation in relationship to the in situ stress direction.

When zones of overstressed rock, such as those illustrated in Fig. 22, are unavoidable, appropriate support systems have to be designed in order to restrict the propagation of fracture of rock contained in these zones. Unfortunately, the analysis presented in this example cannot be used to predict the extent and direction of fracture propagation from the zones of overstressed rock and the choice of support systems tends to be based on very crude approximations.

Such approximations involve designing a system of rock bolts with sufficient capacity to support the weight of the rock contained in the overhead overstressed zones and of sufficient length to permit anchoring in the rock outside these zones.

Improved techniques for support design are being developed, but are not yet generally available for complex failure patterns such as that illustrated in Fig. 22. These techniques, discussed by Hoek \& Brown (1980a), involve an analysis of the interaction between displacements, induced by fracturing in the rock surrounding the tunnel, and the response of the support system installed to control these displacements. It is hoped that these support-interaction analyses will eventually be developed to the point where they can be used to evaluate the support requirements for tunnels such 
Table 5. Stability analysis of slope shown in Fig. $\mathbf{2 3}$

\begin{tabular}{|c|c|c|c|c|c|c|c|c|c|}
\hline Slice & 1 & 2 & 3 & 4 & 5 & 6 & 7 & 8 & 9 \\
\hline $\begin{array}{l}\text { XT } \\
\text { YT } \\
\text { XW } \\
\text { YW } \\
\text { XB } \\
\text { YB }\end{array}$ & $\begin{array}{l}20 \\
50 \\
20 \\
50 \\
20 \\
50\end{array}$ & $\begin{array}{r}135 \\
150 \\
106 \\
100 \\
82 \\
60\end{array}$ & $\begin{array}{r}170 \\
150 \\
162 \\
132 \\
140 \\
68\end{array}$ & $\begin{array}{l}288 \\
250 \\
284 \\
196 \\
274 \\
115\end{array}$ & $\begin{array}{l}312 \\
250 \\
308 \\
210 \\
300 \\
123\end{array}$ & $\begin{array}{l}450 \\
350 \\
530 \\
300 \\
580 \\
265\end{array}$ & $\begin{array}{l}580 \\
410 \\
635 \\
311 \\
635 \\
311\end{array}$ & $\begin{array}{l}660 \\
450 \\
710 \\
380 \\
710 \\
380\end{array}$ & $\begin{array}{l}765 \\
450 \\
765 \\
450 \\
765 \\
450\end{array}$ \\
\hline $\begin{array}{l}\text { Unit weight } \gamma: \\
\mathrm{MN} / \mathrm{m}^{3}\end{array}$ & 0.023 & 0.023 & 0.023 & 0.023 & 0.023 & 0.019 & 0.019 & 0.019 & $\begin{array}{c}\text { Factor of } \\
\text { safety }\end{array}$ \\
\hline $\begin{array}{l}\text { First iteration } \\
\phi_{\mathbf{B}^{\prime}} \\
c_{\mathrm{B}}^{\prime} \\
\phi_{\mathbf{S}^{\prime}} \\
c_{\mathbf{S}^{\prime}} \\
\sigma_{\mathbf{B}^{\prime}} \\
\sigma_{\mathrm{S}^{\prime}}\end{array}$ & $\begin{array}{l}30 \\
1 \cdot 0 \\
0 \\
0 \\
1 \cdot 32 \\
0\end{array}$ & $\begin{array}{l}30 \\
1 \cdot 0 \\
30 \\
1.0 \\
0.77 \\
0.09\end{array}$ & $\begin{array}{l}30 \\
1 \cdot 0 \\
30 \\
1 \cdot 0 \\
1 \cdot 40 \\
0.55\end{array}$ & $\begin{array}{l}30 \\
1 \cdot 0 \\
30 \\
1 \cdot 0 \\
1 \cdot 57 \\
0 \cdot 66\end{array}$ & $\begin{array}{l}30 \\
1.0 \\
30 \\
1 \cdot 0 \\
1.89 \\
0.75\end{array}$ & $\begin{array}{l}18 \\
0 \\
15 \\
0 \\
0 \cdot 58 \\
2 \cdot 01\end{array}$ & $\begin{array}{c}18 \\
0 \\
18 \\
0 \\
1 \cdot 38 \\
1 \cdot 21\end{array}$ & $\begin{array}{l}18 \\
0 \\
18 \\
0 \\
0 \cdot 54 \\
0 \cdot 52\end{array}$ & 1.69 \\
\hline $\begin{array}{l}\text { Second iteration } \\
\phi_{\mathrm{B}}^{\prime} \\
\mathcal{c}_{\mathrm{B}}^{\prime} \\
\phi_{\mathrm{S}^{\prime}} \\
c_{\mathrm{S}}^{\prime} \\
\sigma_{\mathrm{B}}^{\prime} \\
\sigma_{\mathrm{s}}^{\prime}\end{array}$ & $\begin{array}{l}40 \cdot 03 \\
0 \cdot 48 \\
0 \\
0 \\
0 \cdot 74 \\
0\end{array}$ & $\begin{array}{r}45 \cdot 08 \\
0 \cdot 32 \\
62 \cdot 08 \\
0 \cdot 06 \\
1 \cdot 07 \\
0 \cdot 16\end{array}$ & $\begin{array}{r}39 \cdot 46 \\
0 \cdot 51 \\
48 \cdot 11 \\
0 \cdot 25 \\
1 \cdot 31 \\
0 \cdot 46\end{array}$ & $\begin{array}{r}38 \cdot 36 \\
0 \cdot 55 \\
46 \cdot 48 \\
0 \cdot 28 \\
1 \cdot 76 \\
0 \cdot 53\end{array}$ & $\begin{array}{r}36 \cdot 58 \\
0 \cdot 64 \\
45 \cdot 32 \\
0 \cdot 31 \\
1.96 \\
0.62\end{array}$ & $\begin{array}{l}18 \\
0 \\
15 \\
0 \\
0 \cdot 57 \\
2 \cdot 00\end{array}$ & $\begin{array}{l}18 \\
0 \\
18 \\
0 \\
1 \cdot 37 \\
1 \cdot 19\end{array}$ & $\begin{array}{c}18 \\
0 \\
18 \\
0 \\
0.53 \\
0.51\end{array}$ & 1.57 \\
\hline $\begin{array}{l}\text { Third iteration } \\
\phi_{\mathrm{B}^{\prime}} \\
c_{\mathrm{B}}^{\prime} \\
\phi_{\mathrm{S}^{\prime}} \\
c_{\mathrm{S}^{\prime}} \\
\sigma_{\mathbf{B}^{\prime}} \\
\sigma_{\mathrm{S}}^{\prime}\end{array}$ & $\begin{array}{l}45 \cdot 44 \\
0 \cdot 31 \\
0 \\
0 \\
0 \cdot 74 \\
0\end{array}$ & $\begin{array}{r}42 \cdot 02 \\
0 \cdot 41 \\
58 \cdot 10 \\
0 \cdot 10 \\
1 \cdot 07 \\
0 \cdot 15\end{array}$ & $\begin{array}{r}40 \cdot 10 \\
0 \cdot 48 \\
49 \cdot 67 \\
0 \cdot 21 \\
1 \cdot 31 \\
0 \cdot 44\end{array}$ & $\begin{array}{r}37.26 \\
0.61 \\
48.44 \\
0.24 \\
1.76 \\
0.52\end{array}$ & $\begin{array}{r}36.23 \\
0.66 \\
47.04 \\
0.27 \\
1.96 \\
0.61\end{array}$ & $\begin{array}{l}18 \\
0 \\
15 \\
0 \\
0 \cdot 57 \\
2 \cdot 00\end{array}$ & $\begin{array}{c}18 \\
0 \\
18 \\
0 \\
1 \cdot 37 \\
1 \cdot 19\end{array}$ & $\begin{array}{c}18 \\
0 \\
18 \\
0 \\
0 \cdot 53 \\
0.51\end{array}$ & 1.57 \\
\hline
\end{tabular}

as that considered in this example.

\section{Example 2}

This example involves a study of the stability of a very large rock slope such as that which would be excavated in an open pit mine. The benched profile of such a slope, having an overall angle of about $30^{\circ}$ and a vertical height of $400 \mathrm{~m}$, is shown in Fig. 23.

The upper portion of the slope is in overburden material comprising mixed sands, gravels and clays. Back-analyses of previous failures in this overburden material, assuming a linear Mohr failure envelope, give a friction angle $\phi^{\prime}=18^{\circ}$ and a cohesive strength $c^{\prime}=0$. The unit weight of this material averages $0.019 \mathrm{MN} / \mathrm{m}^{3}$.

The overburden is separated from the shale forming the lower part of the slope by a fault which is assumed to have a shear strength defined by $\phi^{\prime}=15^{\circ}$ and $c^{\prime}=0$.

No strength data are available for the shale, but examination of rock exposed in tunnels in this material suggests that the rock mass can be rated as 'good quality'. From Table 4, the material constants $m=1$ and $s=0.004$ are chosen as representative of this rock. In order to provide a measure of conservatism in the design, the value of $s$ is downgraded to zero to allow for the influence of stress relaxation which may occur as the slope is excavated. The strength of the intact material is estimated from point load tests (see Hoek \& Brown, 1980a) as $30 \mathrm{MPa}$. The unit weight of the shale is $0.023 \mathrm{MN} / \mathrm{m}^{3}$.

The phreatic surface in the rock mass forming the slope, shown in Fig. 23, is estimated from general knowledge of the hydrogeology of the site and from observations of seepage in tunnels in the slope.

Analysis of the stability of this slope is carried out by means of the non-vertical slice method (Sarma, 1979). This method is ideally suited to many rock slope problems because it permits the incorporation of specific structural features such as the fault illustrated in Fig. 23. This analysis has been slightly modified by the Author, and the equations used in the examples are listed in 


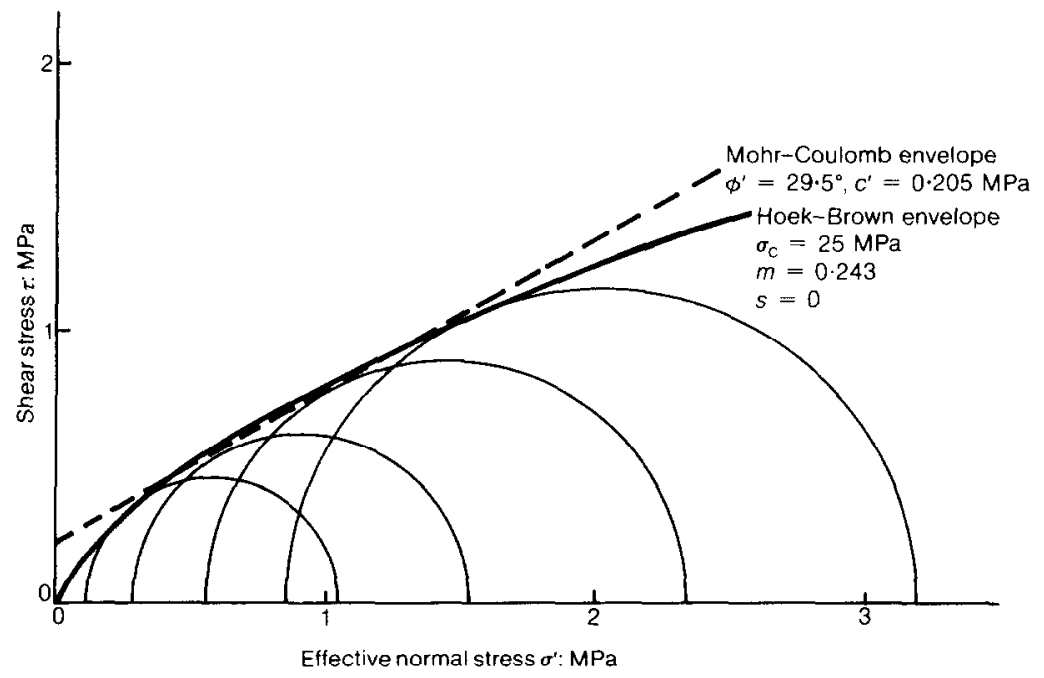

Fig. 24. Mohr circles derived from drained triaxial tests on retorted oil shale waste

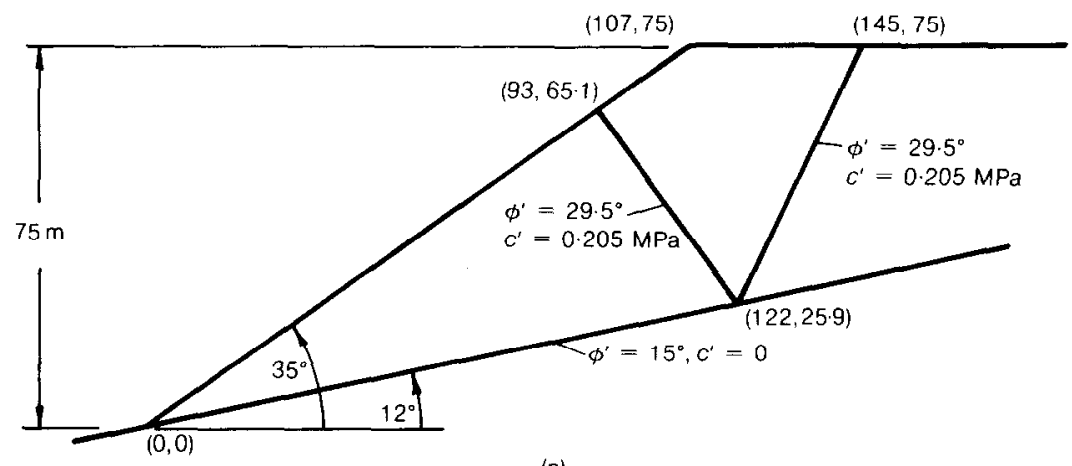

(a)

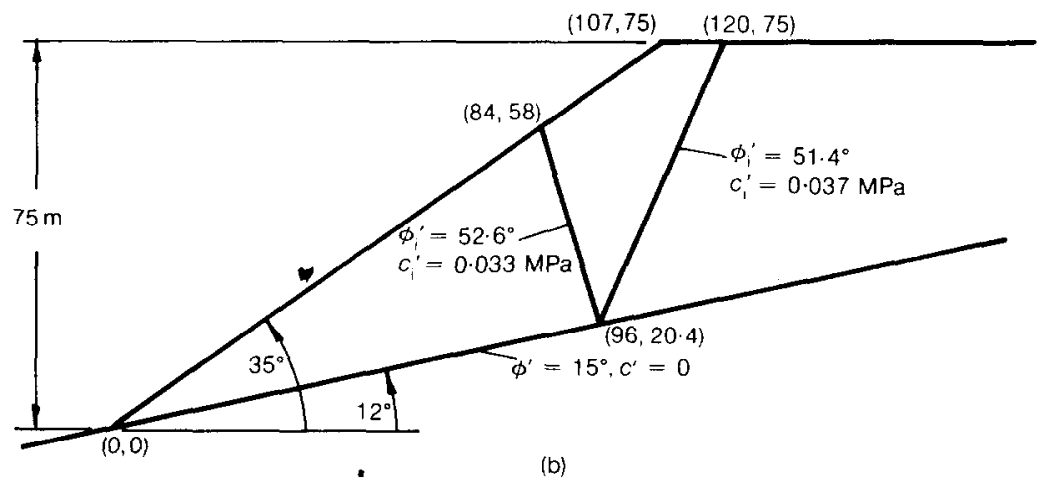

Fig. 25. Analyses of active-passive wedge failure in waste dumps of retorted oil shale resting on weak foundations. (a) Mohr-Coulomb failure criterion, factor of safety $=1 \cdot 41$; (b) HoekBrown failure criterion, factor of safety $=\mathbf{1 . 0 8}$ 
Appendix 2.

Table 5 lists the co-ordinates of the slope profile (XT, YT), the phreatic surface (XW, YW), and the base or failure surface (XB, YB) which was found, from a number of analyses, to give the lowest factor of safety. As a first approximation, the strength of the shale is assumed to be defined by $\phi^{\prime}=30^{\circ}$ and $c^{\prime}=1 \mathrm{MPa}$. Analysis of the slope, using these values, gives a factor of safety of 1.69.

The effective normal stresses $\sigma_{\mathrm{B}}{ }^{\prime}$ and $\sigma_{\mathrm{s}}{ }^{\prime}$ on the slice bases and sides, respectively, are calculated during the course of this analysis and these values are listed, for each slice, in Table 5. These values are used to determine appropriate values for the instantaneous friction angle $\phi_{i}^{\prime}$ and instantaneous cohesive strength $c_{i}^{\prime}$ for the shale by means of equations (6) and (7) (for $\sigma_{\mathrm{c}}=30 \mathrm{MPa}, m=1$ and $s=0$ ). These values of $\phi_{\mathrm{i}}^{\prime}$ and $c_{\mathrm{i}}{ }^{\prime}$ are used in the second iteration of a stability analysis and, as shown in Table 5, the resulting factor of safety is 1.57 .

This process is repeated a third time, using values of $\phi_{i}^{\prime}$ and $c_{i}^{\prime}$ calculated from the effective normal stresses given by the second iteration. The factor of safety given by the third iteration is 1.57. An additional iteration, not included in Table 5, gave the same factor of safety and no further iterations were necessary.

This example is typical of the type of analysis which would be carried out during the feasibility or the basic design phase for a large open pit mine or excavation for a dam foundation or spillway. Further analyses of this type would normally be carried out at various stages during excavation of the slope as the rock mass is exposed and more reliable information becomes available. In some cases, a testing programme may be set up to attempt to investigate the properties of materials such as the shale forming the base of the slope shown in Fig. 23.

\section{Example 3}

A problem which frequently arises in both mining and civil engineering projects is that of the stability of waste dumps on sloping foundations. This problem has been studied extensively by the Commonwealth Scientific and Industrial Research Organization in Australia in relation to spoil pile failures in open cast coal mines (see, for example, Coulthard, 1979). These studies showed that many of these failures involved the same active-passive wedge failure process analysed by Seed \& Sultan (1967, 1969) and Horn \& Hendron (1968) for the evaluation of dams with sloping clay cores.

In considering similar problems, the Author has found that the non-vertical slice method published by Sarma (1979) is well suited to an analysis of this active-passive wedge failure. Identical results to thosc obtained by Coulthard (1979) are given by assuming a drained spoil pile with a purely frictional shear strength on the interface between the active and passive wedges. However, Sarma's method also allows the analysis of a material with non-linear failure characteristics and, if necessary, with ground water pressures in the pile.

The example considered here involves a $75 \mathrm{~m}$ high spoil pile with a horizontal upper surface and a face angle of $35^{\circ}$. The unit weight of the spoil material is $0.015 \mathrm{MN} / \mathrm{m}^{3}$. This pile rests on a weak foundation inclined at $12^{\circ}$ to the horizontal. The shear strength of the foundation surface is defined by a friction angle of $\phi^{\prime}=15^{\circ}$ and zero cohesion. The pile is assumed to be fully drained.

Triaxial tests on retorted oil shale material forming the soil pile give the Mohr circles plotted in Fig. 24. Regression analysis of the triaxial test data, assuming a linear Mohr failure envelope, gave $\phi^{\prime}=29.5^{\circ}$ and $c^{\prime}=0.205 \mathrm{MPa}$ with a correlation coefficient of 1 . Analysis of the same data, using the 'broken rock' analysis given in Appendix 1, for $\sigma_{\mathrm{c}}=25 \mathrm{MPa}$ (determined by point load testing) gave $m=0.243$ and $s=0$. Both linear and non-linear Mohr failure envelopes are plotted in Fig. 24, and both of these envelopes will be used for the analysis of spoil pile stability.

Figure 25 gives the results of stability analyses for the Mohr-Coulomb and Hoek-Brown failure criteria. These analyses were carried out by optimizing the angle of the interface between the active and passive wedge, followed by the angle of the back scarp followed by the distance of the back scarp behind the crest of the spoil pile. In each case, these angles and distances were varied to find the minimum factor of safety in accordance with the procedure suggested by Sarma (1979).

The factor of safety obtained for the MohrCoulomb failure criterion $\left(\phi^{\prime}=29 \cdot 5^{\circ}\right.$ and $c^{\prime}=0.205 \mathrm{MPa}$ ) was 1.41 , while that obtained for the Hoek-Brown criterion $\left(\sigma_{\mathrm{c}}=25 \mathrm{MPa}\right.$, $m=0.243$ and $s=0$ ) was 1.08 . In studies on the reason for the difference between these two factors of safety, it was found that the normal stresses acting across the interface between the active and passive wedges and on the surface forming the back scarp range from 0.06 to $0.11 \mathrm{MPa}$. As can be seen from Fig. 24, this is the normal stress range in which no test data exists and where the linear Mohr-Coulomb failure envelope, fitted to test data at higher normal stress levels, tends to overestimate the available shear strength.

This example illustrates the importance of carrying out triaxial or direct shear tests at the effective normal stress levels which occur in the actual problem being studied. In the example considered here, it would have been more appropriate to carry out a preliminary stability analysis, 
based on assumed parameters, before the testing programme was initiated. In this way, the correct range of normal stresses could have been used in the tests. Unfortunately, as frequently happens in the real engineering world, limits of time, budget and available equipment means that it is not always possible to achieve the ideal testing and design sequence.

\section{CONCLUSION}

An empirical failure criterion for estimating the strength of jointed rock masses has been presented. The basis for its derivation, the assumptions made in its development, and its advantages and limitations have all been discussed. Three examples have been given to illustrate the application of this failure criterion in practical geotechnical engineering design.

From this discussion and from some of the questions left unanswered in the examples, it will be evident that a great deal more work remains to be done in this field. A better understanding of the mechanics of jointed rock mass behaviour is a problem of major significance in geotechnical engineering, and it is an understanding to which both the traditional disciplines of soil mechanics and rock mechanics can and must contribute. The Author hopes that the ideas presented will contribute toward this understanding and development.

\section{ACKNOWLEDGEMENTS}

The Author wishes to acknowledge the encouragement, assistance and guidance provided over many years by Professor E. T. Brown and Dr J. W. Bray of Imperial College. Many of the ideas presented originated from discussions with these colleagues and co-authors.

The stimulating and challenging technical environment which is unique to the group of people who make up Golder Associates is also warmly acknowledged. This environment has provided the impetus and the encouragement required by this Author in searching for realistic solutions to practical engineering problems. Particular thanks are due to Dr R. Hammett, Dr S. Dunbar, Mr M. Adler, Mr B. Stewart, Miss D. Mazurkewich and Miss S. Kerber for their assistance in the preparation of this Paper.

APPENDIX 1. DETERMINATION OF MATERIAL CONSTANTS FOR EMPIRICAL FAILURE CRITERION

Failure criterion

The failure criterion defined by equation (3)

$$
\sigma_{1}^{\prime}=\sigma_{3}{ }^{\prime}+\left(m \sigma_{c} \sigma_{3}{ }^{\prime}+s \sigma_{c}{ }^{2}\right)^{1 / 2}
$$

can be rewritten as

$$
\begin{array}{r}
y=m \sigma_{\mathrm{c}} x+s \sigma_{\mathrm{c}}{ }^{2} \\
\text { where } y=\left(\sigma_{1}{ }^{\prime}-\sigma_{3}{ }^{\prime}\right)^{2} \text { and } x=\sigma_{3}{ }^{\prime}
\end{array}
$$

Intact rock

For intact rock, $s=1$ and the uniaxial compressive strength $\sigma_{\mathrm{c}}$ and the material constant $m$ are given by

$$
\begin{gathered}
\sigma_{\mathrm{c}}{ }^{2}=\frac{\Sigma y}{n}-\left[\frac{\Sigma x y-\frac{\Sigma x \Sigma y}{n}}{\Sigma x^{2}-\frac{(\Sigma x)^{2}}{n}}\right] \frac{\Sigma x}{n} \\
m=\frac{1}{\sigma_{\mathrm{c}}}\left[\frac{\Sigma x y-\frac{\Sigma x \Sigma y}{n}}{\Sigma x^{2}-\frac{(\Sigma x)^{2}}{n}}\right]
\end{gathered}
$$

The coefficient of determination $r^{2}$ is given by

$$
r^{2}=\frac{(\Sigma x y-\Sigma x \Sigma y / n)^{2}}{\left(\Sigma x^{2}-(\Sigma x)^{2} / n\right)\left(\Sigma y^{2}-(\Sigma y)^{2} / n\right)}
$$

\section{Broken rock}

For broken or heavily jointed rock, the strength of the intact rock pieces is determined by the analysis given above. The value of the constant $m$ for broken or heavily jointed rock is found from equation (18). The value of the constant $s$ is given by

$$
s=\frac{1}{\sigma_{\mathrm{c}}{ }^{2}}\left[\frac{\Sigma y}{n}-m \sigma_{\mathrm{c}} \frac{\Sigma x}{n}\right]
$$

The coefficient of determination is found from equation (19).

When the value of $s$ is very close to zero, equation (20) will sometimes give a small negative value. In such cases, put $s=0$ and calculate the constant $m$ as follows

$$
m=\frac{\Sigma y}{\sigma_{\mathrm{c}} \Sigma x}
$$

When equation (21) is used, equation (19) is not valid.

\section{Mohr envelope}

The Mohr failure envelope is defined by the following equation, derived by Dr J. Bray of Imperial College

$$
\tau=\left(\operatorname{Cot} \phi_{\mathrm{i}}^{\prime}-\operatorname{Cos} \phi_{\mathrm{i}}^{\prime}\right) \frac{m \sigma_{\mathrm{c}}}{8}
$$

where the instantaneous friction angle $\phi_{\mathrm{i}}{ }^{\prime}$ is given by

$$
\phi_{i}{ }^{\prime}=\operatorname{Arctan}\left(4 h \operatorname{Cos}^{2}\left(30+\frac{1}{3} \operatorname{Arcsin} h^{-2 / 3}\right)-1\right)^{-1 / 2}
$$

where

$$
h=1+\frac{16\left(m \sigma^{\prime}+s \sigma_{c}\right)}{3 m^{2} \sigma_{c}}
$$

and the instantaneous cohesive strength $c_{i}^{\prime}$ is given by

$$
c_{i}^{\prime}=\tau-\sigma^{\prime} \text { Tan } \phi_{i}^{\prime}
$$

where $\sigma^{\prime}$ is the effective normal stress.

\section{Determination of $m$ and $s$ from direct shear test data}

The following method for determination of the material constants $m$ and $s$ from direct shear test data was devised by $\mathrm{Dr}$ S. Dunbar (unpublished report) of Golder Associates in Vancouver. 

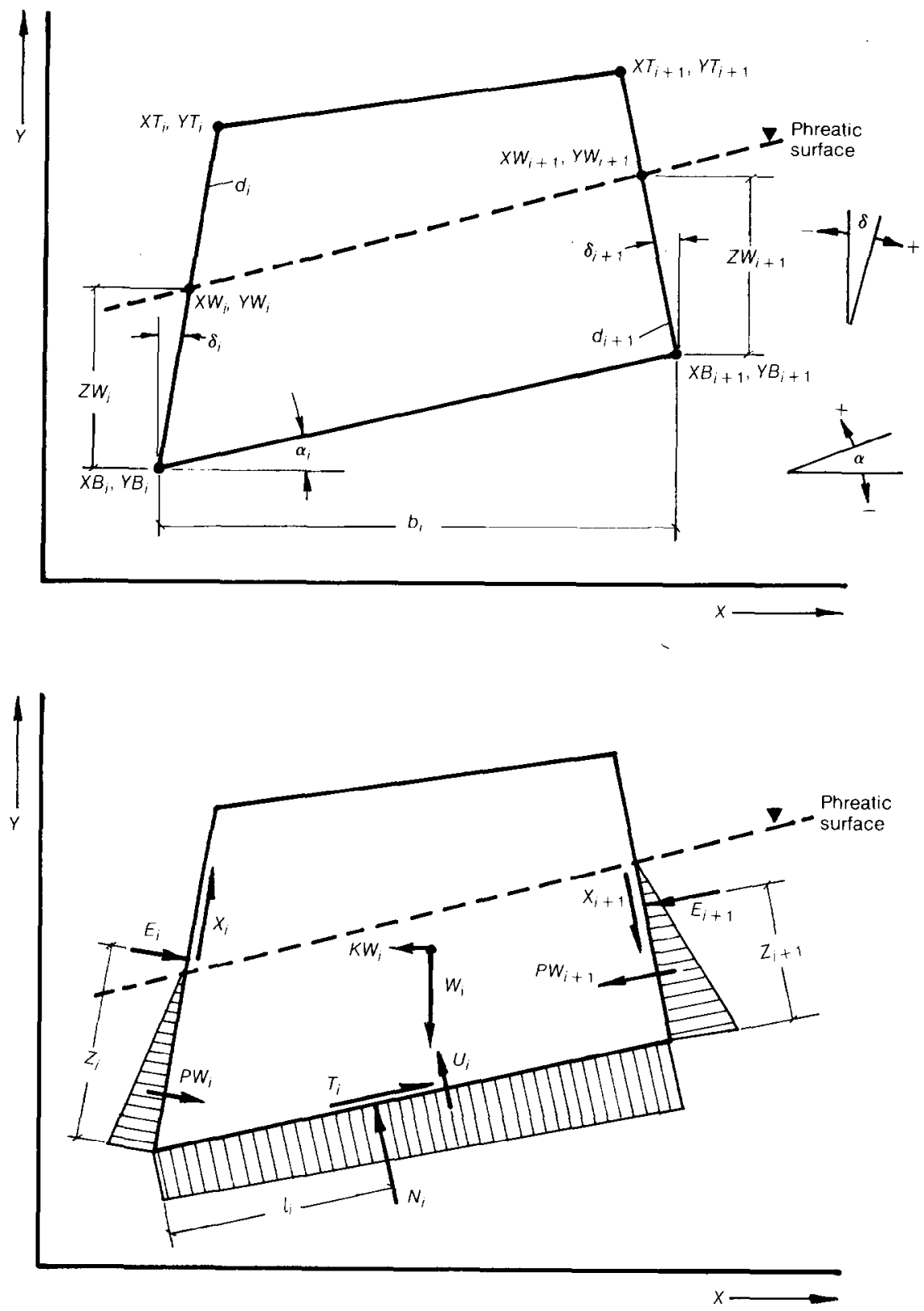

Fig. 26. Geometry of and forces acting on a single slice in the Sarma (1979) non-vertical method for stability analysis 
The major and minor principal stresses $\sigma_{1}{ }^{\prime}$ and $\sigma_{3}{ }^{\prime}$ corresponding to each $\tau, \sigma^{\prime}$ pair can be calculated as follows

$$
\begin{aligned}
& \sigma_{1}{ }^{\prime}=\frac{\left(\sigma^{\prime 2}+\left(\tau-c^{\prime}\right) \tau\right)+\tau\left(\sigma^{\prime 2}+\left(\tau-c^{\prime}\right)^{2}\right)^{1 / 2}}{\sigma^{\prime}} \\
& \sigma_{3}{ }^{\prime}=\frac{\left(\sigma^{\prime 2}+\left(\tau-c^{\prime}\right) \tau\right)-\tau\left(\sigma^{\prime 2}+\left(\tau-c^{\prime}\right)^{2}\right)^{1 / 2}}{\sigma^{\prime}}
\end{aligned}
$$

where $c^{\prime}$ is an estimate of the cohesion intercept for the entire $\tau, \sigma^{\prime}$ data set. This estimate can be an assumed value greater than or equal to zero or it can be determined by linear regression analysis of the shear test results.

After the calculation of the values of $\sigma_{1}{ }^{\prime}$ and $\sigma_{3}{ }^{\prime}$ by means of equations (25) and (26), the determination of the material constants $m$ and $s$ is carried out as for broken rock.

An estimate of the uniaxial compressive strength $\sigma_{c}$ of the intact rock is required in order to complete the analysis.

\section{APPENDIX 2. SARMA NON-VERTICAL SLICE METHOD FOR THE ANALYSIS OF SLOPE FAILURE ON SURFACES OF GENERAL SHAPE \\ Introduction}

This analysis, published by Sarma (1979), is a general method of limit equilibrium analysis which can be used to determine the stability of slopes of a variety of shapes. Slopes with complex profiles sliding on circular, noncircular or plane surfaces or any combination of such surfaces can usually be analysed by this method. In addition, active-passive wedge failures such as those which occur in spoil piles on sloping foundations or in clay core embankments can also be analysed. The analysis allows different shear strengths (defined by cohesion and angle of friction) to be specified for each slice base and side. The freedom to change the inclination of the sides of the slice also allows the incorporation of specific structural features such as faults. Water pressures acting on the sides and base of each slice are included in the analysis. External forces due to water pressure in tension cracks or to reinforcement installed in the slope can be incorporated but have not been included in this version.

The geometry of the sliding mass is defined by the coordinates of the corners of a number of three- or foursided elements. The phreatic surface is defined by the coordinates of its intersections with the slice sides. A closed form solution is then used to calculate the critical horizontal acceleration $K_{\mathrm{c}}$ required to induce a state of limiting equilibrium in the slope. The static factor of safety of the slope is then found by reducing the values of Tan $\phi$ and $c$ to $\operatorname{Tan} \phi / F$ and $c / F$ (where $F$ is the factor of safety) until $K_{\mathrm{c}}=0$.

In order to determine whether the analysis is acceptable, a final check is carried out to assess whether all the effective normal stresses acting across the bases and sides of the slices are positive. If negative stresses are found, the slice geometry must be varied until these negative stresses are eliminated. An additional check on moment equilibrium is also recommended for critical slopes.

The equations listed here have been arranged for programming on a Hewlett Packard 41CV calculator and a full analysis (excluding the moment equilibrium check) can be carried out for ten slices. These equations differ slightly from those published by Sarma (1979) in that a more complete equation is used for the calculation of the effective normal stress on the slice base. This calculation is essential for the analysis of failure of slopes in materials with a non-linear failure criterion.

\section{Geometrical calculations}

The geometry of the $i$ th slice is defined in Fig. 26. Assuming that $Z W_{i}, \delta_{i}$ and $d_{i}$ are available from the previous slice

$$
\begin{aligned}
& d_{i+1}=\left(\left(X T_{i+1}-X B_{i+1}\right)^{2}+\left(Y T_{i+1}-Y B_{i+1}\right)^{2}\right)^{1 / 2} \\
& \delta_{i+1}=\operatorname{Arcsin}\left(\left(X T_{i+1}-X B_{i+1}\right) / d_{i+1}\right) \\
& b_{i}=X B_{i+1}-X B_{i} \\
& \alpha_{i}=\operatorname{Arctan}\left(\left(Y B_{i+1}-Y B_{i}\right) / b_{i}\right) \\
& W_{i}=\frac{1}{2} \gamma\left(\left(Y B_{i}-Y T_{i+1}\right)\left(X T_{i}-X B_{i+1}\right)\right. \\
& \left.+\left(Y T_{i}-Y B_{i+1}\right)\left(X T_{i+1}-X B_{i}\right)\right) \\
& Z W_{i+1}=\left(Y W_{i+1}-Y B_{i+1}\right) \\
& U_{i}=\frac{1}{2} \gamma_{w}\left(Z W_{i}+Z W_{i+1}\right) b_{i} \cdot \operatorname{Sec} \alpha_{i} \\
& P W_{i}=\frac{1}{2} \gamma_{w} Z W_{i}^{2} \operatorname{Sec} \delta_{i} \\
& P W_{i+1}=\frac{1}{2} \gamma_{w} Z W_{i+1}{ }^{2} \operatorname{Sec} \delta_{i+1}
\end{aligned}
$$

where $\gamma$ and $\gamma_{w}$ are the unit weights of rock and water respectively.

Calculation of critical acceleration $K_{\mathrm{c}}$

$$
\begin{aligned}
& a_{n}+a_{n-1} \cdot e_{n}+a_{n-2} \cdot e_{n} \cdot e_{n-1}+\ldots \\
& K_{\mathrm{c}}=+a_{1} \cdot e_{n} \cdot e_{n-1} \ldots e_{3} e_{2} \\
& p_{n}+p_{n-1} \cdot e_{n}+p_{n-2} \cdot e_{n} \cdot e_{n-1}+\ldots \\
&+p_{1} \cdot e_{n} \cdot e_{n-1} \ldots e_{3} e_{2}
\end{aligned}
$$

where

$$
\begin{aligned}
a_{i}= & Q_{i}\left(W_{i} \cdot \operatorname{Sin}\left(\phi_{B i}-\alpha_{i}\right)+R_{i} \cdot \operatorname{Cos} \phi_{B i}\right. \\
& +S_{i+1} \cdot \operatorname{Sin}\left(\phi_{B i}-\alpha_{i}-\delta_{i+1}\right) \\
& \left.-S_{i} \cdot \operatorname{Sin}\left(\phi_{B i}-\alpha_{i}-\delta_{i}\right)\right) \\
p_{i}= & Q_{i} \cdot W_{i} \cdot \operatorname{Cos}\left(\phi_{B i}-\alpha_{i}\right) \\
e_{i}= & Q_{i}\left(\operatorname{Cos}\left(\phi_{B i}-\alpha_{i}+\phi_{S i}-\delta_{i}\right) \operatorname{Sec} \phi_{S i}\right. \\
Q_{i}= & \operatorname{Sec}\left(\phi_{B i}-\alpha_{i}+\phi_{S i+1}-\delta_{i+1}\right) \cdot \operatorname{Cos} \phi_{S i+1} \\
S_{i}= & \left(c_{S i} \cdot d_{i}-P W_{i} \cdot \operatorname{Tan} \phi_{S i}\right) \\
S_{i+1}= & \left(c_{S i+1} \cdot d_{i+1}-P W_{i+1} \cdot \operatorname{Tan} \phi_{S i+1}\right) \\
R_{i}- & \left(c_{B i} \cdot b_{i} \cdot \operatorname{Sec} \alpha_{i}-U_{i} \cdot \operatorname{Tan} \phi_{B i}\right)
\end{aligned}
$$

\section{Calculation of factor of safety $F$}

For slopes where $K_{s} \neq 0$, the factor of safety is calculated by reducing the shear strength simultaneously on all sliding surfaces until the acceleration $K$ calculated by means of equation (36) is equal to zero. This is achieved by substitution, in equation (37) to (43) of the following shear strength values 


$$
\begin{aligned}
& c_{B i} / F, \quad \operatorname{Tan} \phi_{B i} / F, \quad c_{S i} / F, \\
& \operatorname{Tan} \phi_{S i} / F, \quad c_{S i+1} / F \text { and } \operatorname{Tan} \phi_{S i+1} / F
\end{aligned}
$$

Check on acceptability of solution

Having determined the value of $K$ for a given factor of safety, the forces acting on the sides and bases of the slices are found by progressive solution of the following equations, starting from the known condition that $E_{1}=0$.

$$
\begin{aligned}
E_{i+1}= & a_{i}-p_{i} \cdot K+E_{i} \cdot e_{i} \\
X_{i}= & \left(E_{i}-P W_{i}\right) \operatorname{Tan} \phi_{S i}+c_{S i} \cdot d_{i} \\
N_{i}= & \left(W_{i}+X_{i+1} \cdot \operatorname{Cos} \delta_{i+1}-X_{i} \cdot \operatorname{Cos} \delta_{i}\right. \\
& -E_{i+1} \cdot \operatorname{Sin} \delta_{i+1}+E_{i} \cdot \operatorname{Sin} \delta_{i} \\
& \left.+U_{i} \cdot \operatorname{Tan} \phi_{B i} \cdot \operatorname{Sin} \alpha_{i}-c_{B i} \cdot b_{i} \cdot \operatorname{Tan} \alpha_{i}\right) \\
& \times \operatorname{Cos} \phi_{B i} \cdot \operatorname{Sec}\left(\phi_{B i}-\alpha_{i}\right) \\
T_{i}= & \left(N_{i}-U_{i}\right) \operatorname{Tan} \phi_{B i}+c_{B i} \cdot b_{i} \cdot \operatorname{Sec} \alpha_{i}
\end{aligned}
$$

The effective normal stresses acting across the base and the sides of a slice are calculated as follows

$$
\begin{aligned}
\sigma_{B i}{ }^{\prime} & =\left(N_{i}-U_{i}\right) / b_{i} \cdot \operatorname{Sec} \alpha_{i} \\
\sigma_{S i}{ }^{\prime} & =\left(E_{i}-P W_{i}\right) / d_{i} \\
\sigma_{S i+1}{ }^{\prime} & =\left(E_{i+1}-P W_{i+1}\right) / d_{i+1}
\end{aligned}
$$

In order for the solution to be acceptable, all effective normal stresses must be positive.

A final check recommended by Sarma is for moment equilibrium. Referring to Fig. 26 and taking moments about the lower left hand corner of the slice

$$
\begin{aligned}
N_{i} I_{i} & -X_{i+1} \cdot b_{i} \cdot \operatorname{Sec} \alpha_{i} \cdot \operatorname{Cos}\left(\alpha_{i}+\delta_{i+1}\right) \\
& -E_{i} Z_{i}+E_{i+1}\left(Z_{i+1}+b_{i} \cdot \operatorname{Sec} \alpha_{i} \cdot \operatorname{Sin}\left(\alpha_{i}+\delta_{i+1}\right)\right) \\
& -W_{i}\left(X G_{i}-X_{B i}\right)+K_{c} W_{i}\left(Y G_{i}-Y_{B i}\right)=0
\end{aligned}
$$

where $X G_{i}, Y G_{i}$ are the co-ordinates of the centre of gravity of the slice.

Starting from the first slice, where $Z_{1}=0$, assuming a value for $l_{i}$, the moment arm $Z_{i+1}$ can be calculated or vice versa. The values of $Z_{i}$ and $Z_{i+1}$ should lie within the slice boundary, preferably in the middle third.

\section{REFERENCES}

Barton, N. R. (1971). A relationship between joint roughness and joint shear strength. Proc. Int. Symp. Rock Fracture, Nancy, France, 1-8.

Barton, N. R. (1973). Review of a new shear strength criterion for rock joints. Engng Geol. 7, 287--332.

Barton, N. R. (1974). A review of the shear strength of filled discontinuities in rock. Publication No. 105. Oslu: Norwegian Geotechnical Institute.

Barton, N. R. \& Choubey, V. (1977). The shear strength of rock joints in theory and practice. Rock Mech. 10, No. 1, 1-54.

Barton, N. R., Lien, R. \& Lunde, J. (1974). Engineering classification of rock masses for the design of tunnel support. Rock Mech. 6, No. 4, 189-236.

Bieniawski, Z. T. (1974a). Estimating the strength of rock materials. Jl S. Afr. Inst. Min. Metall. 74, No. 8, 312-320.

Bieniawski, Z. T. (1974b). Geomechanics classification of rock masses and its application in tunnelling. Proc. 3rd Int. Congr. Soc. Rock Mech. Denver 2, Part A, 27-32.

Bishop, A. W., Webb, D. L. \& Lewin, P. I. (1965). Undisturbed samples of London clay from the Ashford Common shaft. Géotechnique 15, No. 1, 1-31.

Bishop, A. W. \& Garga, V. K. (1969). Drained tension tests on London clay. Géotechnique 19, No. 2, $309-313$.

Brace, W. F. (1964). Brittle fracture of rocks. In State of stress in the earth's crust (ed. W. R. Judd) pp. 111-174. New York: Flsevier.

Brace, W. F. \& Martin, R. J. (1968). A test of the law of effective stress for crystalline rocks of low porosity. Int. J. Rock Mech. Min. Sci. 5, No. 5, 415-426.

Broch, E. (1974). The influence of water on some rock properties. Proc. 3rd Int. Congr. Soc. Rock Mech. Denver, 2, Part A, 33-38.

Brown, E. T. (1970). Strength of models of rock with intermittent joints. J. Soil Mech. Fdns Div. Am. Soc. Civ. Engrs 96, SM6, 1935-1949.

Brown, E. T. \& Trollope, D. H. (1970). Strength of a model of jointed rock. J. Soil Mech. Fdns Div. Am. Soc. Civ. Engrs 96, SM2, 685-704.

Charles, J. A. \& Watts, K. S. (1980). The influence of confining pressure on the shear strength of compacted rockfill. Géotechnique 30, No. 4, 353-367.

Colback, P. S. B. \& Wiid, B. L. (1965). The influence of moisture content on the compressive strength of rock. Proc. 3rd Can. Rock Mech. Symp. Toronto, 57-61.

Coulthard, M. A. (1979). Back analysis of observed spoil failures using a two-wedge method. Australian CSIRO Division of Applied Geomechanics. Technical report No. 83. Melbourne: CSIRO.

Einstein, H. H., Nelson, R. A., Bruhn, R. W. \& Hirschfeld, R. C. (1969). Model studies of jointed rock behaviour. Proc. 11th Symp. Rock Mech. Berkeley, Calif. 83-103.

Franklin, J. A. \& Hoek, E. (1970). Developments in triaxial testing equipment. Rock Mech. 2, 223-228.

Gerogiannopoulos, N. G. A. (1979). A critical state approach to rock mechanics. PhD thesis, University of London.

Goodman, R. E. (1970). The deformability of joints. In Determination of the in-situ modulus of deformation of rock. ASTM Special Technical Publication No. 477, pp. 174-196. Philadelphia: American Society for Testing and Materials.

Griffith, A. A. (1921). The phenomena of rupture and flow in solids. Phil. Trans. $R$. Soc. A, 221, 163-198.

Griffith, A. A. (1925). Theory of rupture. Proc. 1st Congr. Appl. Mech. Delft, 1924, pp. 55-63. Delft: Technische Bockhandel en Drukkerij.

Handin, J., Hager, R. V., Friedman, M. \& Feather, J. N. (1963). Experimental deformation of sedimentary rocks under confining pressure; pore pressure tests. Bull. Am. Ass. Petrol. Geol. 47, 717-755.

Heard, H. C., Abey, A. E., Bonner, B. P. \& Schock, R. N. (1974). Mechanical behaviour of dry Westerley granite at high confining pressure UCRL Report 51642. California: Lawrence Livermore Laboratory.

Hencher, S. R. \& Richards, L. R. (1982). The basic frictional resistance of sheeting joints in Hong Kong granite. Hong Kong Engr Feb., 21-25.

Hobbs, D. W. (1970). The behaviour of broken rock under triaxial compression. Int. J. Rock Mech. Min. Sci. 7, 125-148. 
Hoek, E. (1965). Rock fracture under static stress conditions. PhD thesis, University of Capetown.

Hoek, E. (1968). Brittle failure of rock. In Rock mechanics in engineering practice (eds K. G. Stagg \& O. C. Zienkiewicz), pp. 99-124. London: Wiley.

Hoek, E. \& Bieniawski, Z. T. (1965). Brittle fracture propagation in rock under compression. Int. J. Frac. Mech. 1, No. 3, 137-155.

Hoek, E. \& Bray, J. W. (1981). Rock slope engineering (3rd edn). London: Institution of Mining and Metallurgy.

Hoek, E. \& Brown, E. T. (1980a). Underground excavations in rock. London: Institution of Mining and Metallurgy.

Hoek, E. \& Brown, E. T. (1980b). Empirical strength criterion for rock masses. J. Geotech. Engng Div. Am. Soc. Civ. Engrs 106, GT9, 1013-1035.

Horino, F. G. \& Ellikson, M. L. (1970). A method of estimating the strength of rock containing planes of weakness. US Bureau Mines Report Investigation 7449. US: Bureau of Mines.

Horn, H. M. \& Hendron, D. M. (1968). Discussion on Stability analysis for a sloping core embankment. J. Soil Mech. Fdns Div. Am. Soc. Civ. Engrs 94, SM3, 777-779.

Jaeger, J. C. (1970). The behaviour of closely jointed rock. Proc. 11th Symp. Rock Mech. Berkeley, Calif. 57-68.

Jaeger, J. C. (1971). Friction of rocks and stability of rock slopes. Géotechnique 21, No. 2, 97-134.

Jaeger, J. C. \& Cook, N. G. W. (1969). Fundamentals of rock mechanics. London: Chapman and Hall.

John, K. W. (1962). An approach to rock mechanics. J. Soil Mech. Fdns Div. Am. Soc. Civ. Engrs 88, SM4, $1-30$.

Krsmanovic, D. (1967). Initial and residual shear strength of hard rock. Géotechnique 17, No. 2. 145-160.

Ladanyi, B. \& Archambault, G. (1970). Simulation of shear behaviour of a jointed rock mass. Proc. 11th Symp. Rock Mech. pp. 105-125. New York: American Institute of Mining, Metallurgical and Petroleum Engineers.

Ladanyi, B. \& Archambault, G. (1972). Evaluation de la resistance au cisaillement d'un massif rocheux fragmente. Proc. 24th Int. Geol. Congr. Montreal. Sec. 130, 249-260.

Lajtai, E. Z. (1967). The influence of interlocking rock discontinuities on compressive strength (model experiments). Rock Mech. Engng Geol. 5, 217-228.

Lama, R. D. \& Vutukuri, V. S. (1978). Handbook on mechanical properties of rocks. Vol. IV-Testing techniques and results. Switzerland: Trans Tech Publications.

Marachi, N. D., Chan, C. K. \& Seed, H. B. (1972). Evaluation of properties of rockfill materials. $J$. Soil Mech. Fdns Div. Am. Soc. Civ. Engrs 98, SM4, 95-114.

Marsal, R. J. (1967). Large scale testing of rockfill materials. J. Soil Mech. Fdns Div. Am. Soc. Civ. Engrs 93, SM2, 27-44.

Marsal, R. J. (1973). Mechanical properties of rockfill. In Embankment dam engineering, Casagrande Vol. pp. 109-200. New York: Wiley.

Martin, G. R. \& Miller (1974). Joint strength characteristics of a weathered rock. Proc. 3rd Int. Congr. Soc. Rock Mech. Denver, 2, Part A, 263-270.

McClintock, F. A. \& Walsh, J. B. (1962). Friction on Griffith cracks under pressure. Proc. 4th US Congr.
Appl. Math., Berkeley. 1015-1021.

McLamore, R. \& Gray, K. E. (1967). The mechanical behaviour of anisotropic sedimentary rocks. Trans. Am. Soc. Mech. Engrs Series B, 62-76.

Misra, B. (1972). Correlation of rock properties with machine performance. $\mathrm{PhD}$ thesis. University of Leeds.

Mogi, K. (1966). Pressure dependence of rock strength and transition from brittle fracture to ductile flow. Bull. Earthq. Res. Inst., Tokyo Univ. 44, 215-232.

Mogi, K. (1967). Effect of the intermediate principal stress on rock failure. J. Geophys. Res. 72, No. 20, 51175131.

Muller, L. \& Pacher, F. (1965). Modelvensuch Zur Klarung der Bruchgefahr geklufteter Medien. Rock Mech. Engng Geol. Suppl. No. 2, 7-24.

Murrell, S. A. F. (1958). The strength of coal under triaxial compression. In Mechanical properties of non-metallic brittle materials (ed. W. H. Walton), pp. 123-145. London: Butterworths.

Murrell, S. A. F. (1965). The effect of triaxial stress systems on the strength of rocks at atmospheric temperatures. Geophys. J. 10, 231-281.

Patton, F. D. (1966). Multiple modes of shear failure in rock. Proc. Ist Int. Congr. Rock Mech. Lisbon, 1, 509-513.

Raphael, J. M. \& Goodman, R. E. (1979). Strength and deformability of highly fractured rock. I. Geotech. Engng Div. Am. Soc. Civ. Engrs 105, GT11, 1285-1300.

Richards, L. R. \& Cowland, J. W. (1982). The effect of surface roughness on field shear strength of sheeting joints in Hong Kong granite. Hong Kong Engr Oct., $39-43$.

Rosengren, K. J. \& Jaeger, J. C. (1968). The mechanical properties of a low-porosity interlocked aggregate. Géotechnique 18, No. 3. 317-326.

Sarma, S. K. (1979). Stability analysis of embankments and slopes. J. Geotech. Engng Div. Am. Soc. Civ. Engrs 105, GT12, 1511-1524.

Schwartz, A. E. (1964). Failure of rock in the triaxial shear test. Proc. 6th Symp. Rock Mech. Rolla, Missouri, 109-135.

Seed, H. B. \& Sultan, H. A. (1967). Stability analysis for a sloping core embankment. J. Geotech. Engng Div. Am. Soc. Civ. Engrs 93, SM4, 69-83.

Sultan, H. A. \& Seed, H. B. (1969). Discussion closure. J. Geotech. Engng Div. Am. Soc. Civ. Engrs 95, SM1, 334-335.

Walker, P. E. (1971). The shearing behaviour of a block jointed rock model. PhD thesis, Queens University, Belfast.

Wawersik, W. R. (1968). Detailed analysis of rock failure in laboratory compression tests. PhD thesis, University of Minnesota.

Wawersik, W. R. \& Brace, W. F. (1971). Post-failure behaviour of a granite and a diabase. Rock Mech. 3, No. 2, 61-85.

\section{VOTE OF THANKS}

In proposing a vote of thanks to Dr Hoek, Professor R. E. Gibson said: 'We have listened to a discourse aimed, in the lecturer's own words, 
“. . a at providing a better understanding of the mechanics of jointed rock mass behaviour: a problem of major significance in geotechnical engineering". To those academics among us who have given attention to this problem, it is recognized as one of great difficulty and fascination. To those practising engineers who are obliged to arrive at decisions based on whatever data and understanding they possess, it can be a daunting responsibility. Evert Hoek's wide-ranging career has given him an unusual understanding and appreciation of both these viewpoints so that he perceives what the engineer needs from research and also the extent to which the uncertainties inherent in nature allow this need to be met.

'Dr Hoek has spoken with authority on a subject of great importance to all geotechnical engineers and has succeeded brilliantly in his aim of providing a better understanding of the mechanics of jointed rock. I am sure that in the future this Lecture will be referred to many times.

'I should like on behalf of us all to congratulate Dr Hoek most warmly on his splendid lecture and to propose now a hearty vote of thanks to him'.

The vote of thanks was accorded with acclamation. 